\title{
Effects of feed additives on rumen and blood profiles during a starch and fructose challenge
}

\author{
H. M. Golder, ${ }^{\star} \dagger^{1}$ P. Celi, ${ }^{\star} \ddagger$ A. R. Rabiee, ${ }^{*} \dagger$ and I. J. Lean ${ }^{\star} \dagger$ \\ *Dairy Science Group, Faculty of Veterinary Science, The University of Sydney, Camden, New South Wales, Australia 2570 \\ †SBScibus, Camden, New South Wales, Australia 2570 \\ ¥Melbourne School of Land and Environment, The University of Melbourne, Parkville, Victoria, Australia, 3052
}

\section{ABSTRACT}

We evaluated the effect of feed additives on the risk of ruminal acidosis in Holstein heifers $(\mathrm{n}=40)$ fed starch and fructose in a challenge study. Heifers were randomly allocated to feed additive groups ( $\mathrm{n}=8$ heifers/group): (1) control (no additives); (2) virginiamycin (VM); (3) monensin + tylosin (MT); (4) monensin + live yeast (MLY); and (5) sodium bicarbonate + magnesium oxide (BUF). Heifers were fed $2.5 \%$ of body weight (BW) dry matter intake (DMI) per day of a total mixed ration (62:38 forage:concentrate) and feed additives for a 20-d adaptation period. Fructose $(0.1 \%$ of $\mathrm{BW} / \mathrm{d}$ ) was included for the last $10 \mathrm{~d}$ of the adaptation period. On d 21, heifers were fed to target a DMI of $1.0 \%$ of $\mathrm{BW}$ of wheat, fructose at $0.2 \%$ of $\mathrm{BW}$, and their feed additives. Rumen fluid samples obtained by stomach tube and blood samples were collected weekly as well as during a 3.6-h period on challenge day (d 21). Virginiamycin and BUF groups maintained a consistently high DMI across the 20-d adaptation period. The MLY heifers had low DMI of the challenge ration. Average daily gain and feed conversion ratio were not affected by feed additives. All rumen and plasma measures changed weekly over adaptation and over the challenge sampling period with the exception of rumen total lactate and histamine concentrations, plasma oxidative stress index, and ceruloplasmin. Substantial within- and between-group variation was observed in rumen and plasma profiles at challenge sampling. No significant group changes were observed in rumen total volatile fatty acids, propionate, acetate-to-propionate ratio, isobutyrate, caproate, isovalerate, total lactate, $\mathrm{D}-$ and L-lactate, and $\mathrm{pH}$ measures on challenge day. Acetate concentration was increased in the BUF and control groups on challenge day. Butyrate concentration was lower in the MLY and MT groups compared with other groups at challenge. Valerate concentrations

Received June 21, 2013.

Accepted September 11, 2013.

${ }^{1}$ Corresponding author: heleng@sbscibus.com.au were lowest in the control, VM, and BUF groups and lactate concentrations were numerically lower in the MLY, VM, and BUF groups. Total lactate concentrations were $>10 \mathrm{~m} M$ for each group throughout the challenge. Ammonia concentrations were lower in the MLY and MT groups. Histamine concentrations were decreased in MLY and increased in the VM and BUF groups. Plasma oxidative stress measures were not influenced by feed additives weekly or on challenge day, except for an increase in biological antioxidant potential in the control, VM, and MT groups on challenge day. Despite the large within-animal variation, all feed additives modified rumen function and may influence the risk of acidosis by different mechanisms; however, none stabilized the rumen in all heifers.

Key words: acidosis, feed additive, fructose, lactic acid

\section{INTRODUCTION}

Ruminal acidosis is a complex nutritional disorder. It is caused by the accumulation of organic acids initiated by the combination of consumption of large amounts of readily fermentable carbohydrates and insufficient intake of physically effective fiber (Nagaraja and Titgemeyer, 2007; Bramley et al., 2008). Periods of high risk for acidosis occur when dairy cattle are fed substantially more concentrate close to calving or when beef cattle enter the feedlot. The complex can occur from a relatively mild form where symptoms are subclinical to the peracute, resulting in death. Clinical signs include losses in production performance, diarrhea, dehydration, lameness, and decreased appetite (RAGFAR, 2007; Plaizier et al., 2008). Clinical definitions of acidosis, largely based on rumen $\mathrm{pH}$, are inconsistent and can create confusion, leading to inaccurate diagnosis of acidosis (Kleen et al., 2003; Nagaraja and Titgemeyer, 2007; Plaizier et al., 2008). We largely concur with the view of Britton et al. (1989) that "acidosis is not one disease, but rather a continuum of degrees of ruminal acidity." Perhaps this description could be reworded to "degrees of safe sequestration of hydrogen." 
Inclusion of feed additives is one practice of several used to reduce acidosis risk in the dairy and beef industries. A substantial body of evidence exists that supports the use of feed additives in cattle. However, relatively few papers exist that examine the effects of combinations of these on rumen profiles in vivo in dairy cattle (Clayton et al., 1999; Lean et al., 2000). Scientific evaluation of the effects of feed additives will allow producers, nutritionists, and veterinarians to make informed management decisions when considering their use and assist in the development of the most prudent use strategies for antimicrobial and other agents that modify rumen function.

Our primary aim was to evaluate the efficacy of the following feed additives to reduce acidosis risk during a non-life-threatening, but substantial, starch and fructose challenge: virginiamycin, combinations of monensin and tylosin, monensin and yeast, and sodium bicarbonate and magnesium oxide. We hypothesized that feed additives would reduce acidosis risk in cattle compared with unsupplemented control cattle, as indicated by production, rumen, inflammation, and oxidative stress measures. We also intended to further examine the pathophysiology and clarify definitions of ruminal acidosis.

\section{MATERIALS AND METHODS}

\section{Animals and Housing}

The study was conducted on 36 pregnant and 4 nonpregnant Holstein heifers from a commercial dairy herd $(\mathrm{n}=40)$. All heifers were between 15 to 21 mo of age and had a mean BW of $383 \pm 49 \mathrm{~kg}$ on arrival at the study site located at Cobbitty [New South Wales (NSW), Australia]. For the duration of the study, all heifers, when not being fed or sampled, were kept as 1 herd in a paddock with little or no available feed DM and with ad libitum water access. All experimental procedures were approved by the SBScibus Animal Ethics Committee (SBScibus 0512-0513).

\section{Experimental Design}

Each heifer was enrolled in the study for a period of 29 d, consisting of 5 experimental periods: (1) preadaptation ( $\mathrm{d}-2$ to 0$),(2)$ adaptation I (d 1 to 10), (3) adaptation II (d 11 to 20), (4) challenge (d 21), and (5) postchallenge (d 22 to 26; Figure 1). Heifers were randomly assigned by identification number to 1 of 5 feed additive groups ( $\mathrm{n}=8$ heifers/group) and 1 of 4 blocks (A to D; $\mathrm{n}=10$ heifers/block), with 2 heifers/ group assigned to each block using a random numbers table generated from Stata v.11 (StataCorp LP, College Station, TX). Enrolment into the study was staggered, with heifers assigned to each block entering the study $1 \mathrm{~d}$ after the previous block to allow sampling of 10 heifers/d only, over 4 consecutive days. Sample sizes were based on previous studies in which significant differences in fermentation characteristics were observed (Golder et al., 2012; Lean et al., 2013). To ensure that feeds were allocated correctly, farm workers were not blinded to feed-additive groups.

\section{Feed-Additive Groups}

The feed-additive groups were as follows: (1) control (no additives); (2) virginiamycin (VM); (3) monensin + tylosin (MT); (4) monensin + live yeast (MLY); and (5) sodium bicarbonate + magnesium oxide (BUF). The feed additives (Table 1) were incorporated into wheat pellets mixed on top of each heifer's TMR, with the exception of the yeast, sodium bicarbonate, and magnesium oxide, which were weighed out separately in individual feeding portions and mixed on top of the TMR. All heifers received the same amount of wheat pellets (Figure 1); however, those received by the control and BUF heifers contained no feed additives.

\section{Diet}

The rations offered in each of the experimental periods are detailed in Figure 1. The predicted chemical composition of the rations offered during the adapta-

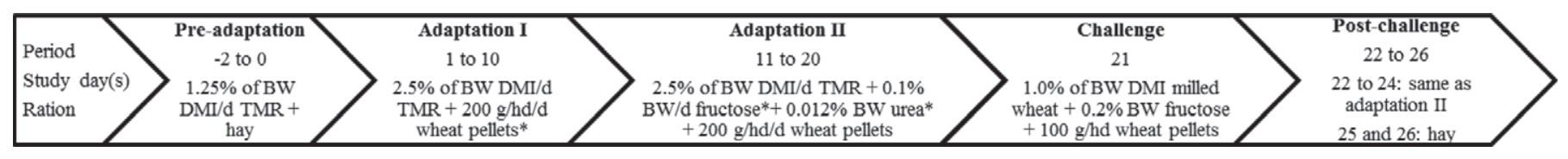

Figure 1. Experimental periods and their corresponding study days and rations offered during the study. The rations were offered in equal proportions twice daily, with the exception of the challenge period. Rumen and blood samples were collected on d $0,7,14$, and 21 during their respective experimental periods. Wheat pellets contained respective feed additives for their groups as indicated in Table 1. Heifers in the monen$\sin +$ live yeast (MLY) group received yeast and those in the sodium bicarbonate + magnesium oxide (BUF) group received sodium bicarbonate and magnesium oxide in addition to wheat pellets. ${ }^{*}$ Introductory doses were offered for the initial days before the full rate was offered. TMR $=$ 62:38 forage:concentrate, consisting of $31.5 \%$ wheaten hay, $30.5 \%$ alfalfa hay, and $38 \%$ milled wheat; hd $=$ head. 


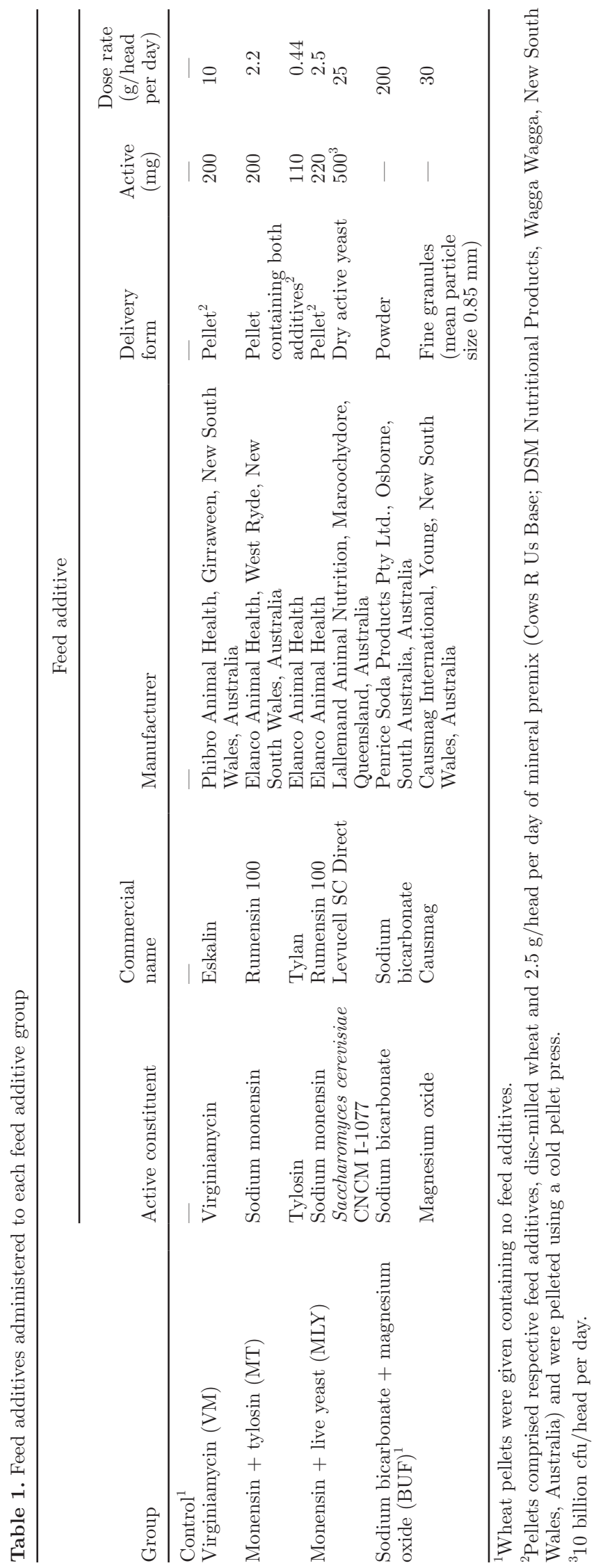

tion I, adaptation II, and challenge periods were calculated using CPM Dairy Ration Analyzer (version 3.10; Cornell-Penn-Miner, Cornell University, Ithaca, NY; Table 2) from ration components analyzed by wet chemistry (Dairy One Cooperative Inc., Forage Testing Laboratory, Ithaca, NY; Table 3). Wet chemistry methods are described in Golder et al. (2012). Samples of the forages were taken by a forage core sampler (Best Harvest USA LLC, Saint Petersburg, FL). Three cores from each bale of hay used in the TMR were pooled for both the wheaten and alfalfa hay.

\section{Feeding Procedure}

All heifers were fed half their daily rations at 0700 and $1400 \mathrm{~h}$ in individual concrete floor feeding pens. The order that heifers were fed and the feeding pen number were ad hoc at each feeding session. Pens were cleaned between heifers and feeding sessions to avoid cross-contamination of feed additives. Each heifer had a single labeled feed bin to prevent feed contamination. The fructose (CornSweet crystalline fructose; ADM Corn Processing, Decatur, IL) and urea [Incitec Pivot Ltd., Melbourne, Victoria (VIC), Australia], when incorporated in the ration (Figure 1), were weighed out daily based on individual BW and mixed on top of the TMR. Observed total eating time and manually weighed orts were recorded for each heifer at each feeding session. No water access was available in the feeding pens or holding yards during the feeding sessions.

\section{Sampling Procedure}

A rumen and blood sample was taken within $3 \mathrm{~h}$ of the morning feed from each heifer on d 0,7 , and 14 during the preadaptation, adaptation I, and adaptation II periods, respectively. Rumen fluid was collected using a custom designed stomach pump and a tube approximately $3 \mathrm{~m}$ in length with a multi-holed aluminum probe at one end into a $500 \mathrm{~mL}$ container. The tube was inserted to a minimum length of approximately $2 \mathrm{~m}$. Rumen fluid was scored for saliva contamination as described by Bramley et al. (2008) using a 3-point scoring system (3 being the highest level of contamination). Rumen fluid collection was repeated up to 3 times if a saliva score of $>1$ was observed and the lowest scoring sample was used for $\mathrm{pH}$ measurement. No rumen samples retained for analysis had a saliva score $>2$. Rumen fluid samples were analyzed for $\mathrm{pH}$ immediately after collection using a $\mathrm{pH}$ meter (Merck Pty Ltd., Kilsyth, VIC, Australia). The samples were sieved to remove large particles and centrifuged (Allegra X-12R; Beckman Coulter Australia Pty. Ltd., Gladesville, NSW, Australia) at 1,512 $\times g$ for $15 \mathrm{~min}$ 
Table 2. Predicted chemical composition of the ration offered during the following periods: (1) adaptation I (comprising TMR DMI at $2.5 \%$ of BW/d $+200 \mathrm{~g}$ of wheat pellets/head per day), (2) adaptation II (comprising TMR DMI at $2.5 \%$ of $\mathrm{BW} / \mathrm{d}+$ fructose $\mathrm{DMI}$ at $0.1 \%$ of $\mathrm{BW} / \mathrm{d}+200 \mathrm{~g}$ of wheat pellets/head per day), and (3) challenge (comprising wheat DMI at $1.0 \%$ of BW + fructose DMI at $0.2 \%$ of BW $+100 \mathrm{~g}$ of wheat pellets/ head per day $)^{1,2}$

\begin{tabular}{|c|c|c|c|}
\hline \multirow[b]{2}{*}{$\begin{array}{l}\text { Item ( } \% \text { of DM, } \\
\text { unless otherwise specified) }\end{array}$} & \multicolumn{3}{|c|}{ Period (study days) } \\
\hline & $\begin{array}{l}\text { Adaptation I } \\
\text { (d } 1 \text { to } 10)\end{array}$ & $\begin{array}{l}\text { Adaptation II } \\
\text { (d } 11 \text { to } 20)\end{array}$ & $\begin{array}{l}\text { Challenge } \\
\quad(\mathrm{d} 21)\end{array}$ \\
\hline $\mathrm{DM}(\%)$ & 89.6 & 89.9 & 90.2 \\
\hline $\mathrm{CP}$ & 13.4 & 14.1 & 9.8 \\
\hline RUP ( $\%$ of CP) & 27.6 & 21.3 & 11.8 \\
\hline $\mathrm{RDP}(\%$ of $\mathrm{CP})$ & 72.4 & 78.7 & 88.2 \\
\hline $\mathrm{RDP}$ & 9.70 & 11.1 & 8.60 \\
\hline Soluble protein ( $\%$ of $\mathrm{CP}$ ) & 39.8 & 45.0 & 38.5 \\
\hline $\mathrm{ADF}$ & 22.4 & 21.6 & 4.49 \\
\hline NDF & 35.0 & 33.6 & 10.7 \\
\hline Forage NDF ( $\%$ of NDF) & 85.8 & 85.8 & 0.0 \\
\hline Forage NDF ( $\%$ of DM) & 30.0 & 28.8 & 0.0 \\
\hline Physically effective NDF & 30.6 & 29.4 & 4.2 \\
\hline Lignin & 3.6 & 3.5 & 0.9 \\
\hline $\mathrm{NFC}^{3}$ & 46.1 & 47.7 & 76.3 \\
\hline Silage acids & 0.0 & 0.0 & 0.0 \\
\hline Sugar & 9.4 & 12.6 & 19.1 \\
\hline Starch & 27.5 & 26.4 & 54.1 \\
\hline Soluble fiber & 9.1 & 8.7 & 3.2 \\
\hline Total ether extract & 1.95 & 1.88 & 1.74 \\
\hline Total long-chain FA & 1.39 & 1.34 & 1.57 \\
\hline Ash & 5.98 & 4.94 & 1.82 \\
\hline DCAD $(\mathrm{mEq} / 100 \mathrm{~g})$ & 24.7 & 23.7 & -0.25 \\
\hline \multicolumn{4}{|l|}{ Mineral $(\mathrm{mg} / \mathrm{kg})$} \\
\hline Chloride & 4,400 & 4,300 & 1,000 \\
\hline Calcium & 4,800 & 4,500 & 900 \\
\hline Copper & 21 & 19 & 20 \\
\hline Iron & 128 & 122 & 42 \\
\hline Phosphorus & 3,000 & 2,900 & 2,800 \\
\hline Potassium & 1,700 & 16,300 & 4,100 \\
\hline Magnesium & 1,400 & 1,300 & 1.000 \\
\hline Manganese & 75 & 70 & 58 \\
\hline Sodium & 1,300 & 1,200 & 100 \\
\hline Sulfur & 1,900 & 1,800 & 1.300 \\
\hline Zinc & 64 & 58 & 62 \\
\hline
\end{tabular}

${ }^{1}$ The TMR (62:38 forage:concentrate) consisted of $31.5 \%$ wheaten hay, $30.5 \%$ alfalfa hay, and $38 \%$ disc-milled wheat.

${ }^{2}$ Estimations were performed using CPM Dairy Analyzer V3.10 (Cornell-Penn-Miner, Cornell University, Ithaca, NY) and were based on a $400 \mathrm{~kg}$ BW heifer with a body condition score of 3.25 and a growth rate of $0.73 \mathrm{~kg} / \mathrm{d}$.

${ }^{3} \mathrm{NFC}=100-[(\mathrm{NDF}-$ neutral detergent-insoluble $\mathrm{CP})+\mathrm{CP}+$ crude fat + ash $]$.

at $5^{\circ} \mathrm{C}$. The supernatant was aliquoted into $1.5-\mathrm{mL}$ collection tubes and stored at $-20^{\circ} \mathrm{C}$ for VFA, ammonia, L- and D-lactate, and histamine analysis.

Blood samples were taken by coccygeal venipuncture using heparinized blood collection tubes (Vacutainer; $\mathrm{BD}$, Plymouth, UK) and centrifuged at $1,512 \times g$ for 15 $\mathrm{min}$ at $5^{\circ} \mathrm{C}$. The plasma was then aliquoted into $1.5-\mathrm{mL}$ storage tubes, and stored at $-20^{\circ} \mathrm{C}$ for histamine and oxidative stress analysis.

\section{Challenge Procedure}

Each heifer was challenged once on d 21 with a DMI of 1.0 and $0.2 \%$ of their BW of milled wheat and fructose, respectively, and fed their morning allocation of feed additives. The NFC of the challenge ration was estimated at $76.3 \%$ of DM (CPM Dairy Ration Analyzer; Table 2). The blocks of heifers were sampled over 4 consecutive days. At $0700 \mathrm{~h}$ on the day of challenge, each heifer was offered $200 \mathrm{~g}$ of alfalfa hay to reduce saliva contamination of the rumen samples. Previously, we found that feeding a small proportion of hay or silage immediately before feeding the challenge rations prevented cattle from salivating excessively before sampling. Immediately after consumption of the hay, heifers were offered their challenge rations. Ration consumption time and weighed orts were recorded to calculate the average ration consumption time and 
Table 3. Chemical composition of the TMR components and their proportions within the TMR: wheaten hay $(31.5 \%)$, alfalfa hay $(30.5 \%)$, and milled wheat $(38.0 \%)^{1}$

\begin{tabular}{|c|c|c|c|}
\hline $\begin{array}{l}\text { Item ( } \% \text { of DM, } \\
\text { unless otherwise specified) }\end{array}$ & $\begin{array}{l}\text { Wheaten } \\
\text { hay }\end{array}$ & $\begin{array}{l}\text { Alfalfa } \\
\text { hay }\end{array}$ & $\begin{array}{l}\text { Milled } \\
\text { wheat }\end{array}$ \\
\hline DM (\%) & 88.3 & 91.5 & 88.5 \\
\hline NDF & 56.3 & 43.8 & 15 \\
\hline $\mathrm{CP}$ & 7.2 & 22.1 & 11.7 \\
\hline Soluble protein ( $\%$ of $\mathrm{CP})$ & 40 & 41 & 39 \\
\hline Crude fat & 1.6 & 2.2 & 2.1 \\
\hline Ash & 6.83 & 9.82 & 1.89 \\
\hline Lignin & 4.1 & 6.6 & 1.3 \\
\hline $\mathrm{ADF}$ & 34.7 & 33.2 & 5.5 \\
\hline Acid detergent-insoluble CP & 0.7 & 1.4 & 1.1 \\
\hline Neutral detergent-insoluble CP & 1.8 & 5.6 & 3.5 \\
\hline $\mathrm{NFC}^{2}$ & 29.8 & 27.6 & 72.8 \\
\hline Available protein & 6.5 & 20.7 & 10.6 \\
\hline Starch & 4.1 & 1.4 & 62.4 \\
\hline Ethanol-soluble carbohydrates (simple sugars) & 17.5 & 9.2 & 3.8 \\
\hline $\operatorname{DCAD}(\mathrm{mEq} / 100 \mathrm{~g})$ & 20 & 58 & -1 \\
\hline \multicolumn{4}{|l|}{ Mineral $(\mathrm{mg} / \mathrm{kg})$} \\
\hline Chloride & 2,800 & 8,000 & 1,200 \\
\hline Calcium & 1,300 & 12,300 & 400 \\
\hline Copper & 6 & 6 & 5 \\
\hline Iron & 229 & 115 & 39 \\
\hline Phosphorus & 1,700 & 3,800 & 3,200 \\
\hline Potassium & 13,200 & 36,900 & 4,800 \\
\hline Magnesium & 900 & 2,000 & 1,100 \\
\hline Manganese & 84 & 33 & 41 \\
\hline Molybdenum & 0.4 & 1.4 & 1 \\
\hline Sodium & 170 & 1,260 & 90 \\
\hline Sulfur & 1,100 & 3,100 & 1,600 \\
\hline Zinc & 10 & 20 & 16 \\
\hline
\end{tabular}

${ }^{1}$ Values are means obtained from near-infrared spectroscopy and wet chemistry from DairyOne (Dairy One Cooperative Inc., Forage Testing Laboratory, Ithaca, NY).

${ }^{2} \mathrm{NFC}=100-[(\mathrm{NDF}-$ neutral detergent-insoluble $\mathrm{CP})+\mathrm{CP}+$ crude fat + ash $]$.

percentage of ration consumed per treatment group. Rumen fluid samples were collected $5,65,115,165$, and 215 min after ration consumption using a stomach tube and pump. A blood sample was taken by coccygeal venipuncture 5 and 215 min after ration consumption. Rumen and blood samples were processed as described in the Sampling Procedure section.

As a result of clinical acidosis in a control heifer from block A $10 \mathrm{~h}$ after challenge feeding, all control heifers from blocks B to D were drenched with $200 \mathrm{~g} /$ head of sodium bicarbonate (Penrice Soda Products Pty Ltd., Osborne, South Australia, Australia) in $10 \mathrm{~L}$ of water within $2 \mathrm{~h}$ of the final sampling. All heifers were monitored closely in the afternoon of the challenge day and offered access to wheaten hay. Heifers were returned to their adaptation II rations for the first $3 \mathrm{~d}$ after challenge and feed intake was recorded.

\section{Locomotion Scoring}

Heifers were locomotion scored on 7 occasions during the study, after rumen and blood sampling in the preadaptation, adaptation I and II periods, on challenge day, and 1,2, and $5 \mathrm{~d}$ after challenge. Scoring was conducted by 2 study investigators working in tandem as heifers were individually walked past them on a concrete surface using the 5-point scoring system developed by Sprecher et al. (1997), with 5 being severely lame. The scorers were blinded to previous scores. Scores $<2$ were considered normal.

\section{BW and Physical Examination}

Individual heifer BW was measured on arrival at the study site and weekly. Ration components based on BW were updated after weighing. All heifers were observed during each feeding session and were given a physical examination if low appetite or abnormal demeanor were observed. The physical examination included rectal temperature, rumen contractions, heart rate, rumen $\mathrm{pH}$ measurement, and optional rumen and blood collection. Heifers with reduced feed intake or diarrhea were closely observed and monitored at subsequent feeding sessions. Any potential health concerns were recorded.

\section{Acidosis Diagnosis}

Clinical ruminal acidosis was diagnosed based on a combination of clinical signs that included inappetence, dull demeanor, abnormal rectal temperature, increased 
respiratory rate, absence of rumen contractions, and lameness. Subclinical acidosis was diagnosed based on a combination of DMI and acidosis eigenvalues obtained from standardized rumen $\mathrm{pH}, \mathrm{VFA}$, ammonia, and lactate concentrations, using the model by Bramley et al. (2008).

\section{Analysis}

Rumen VFA concentrations were analyzed by an Agilent series gas chromatograph with HP6890 injection, $30-\mathrm{mm} \times 0.53-\mathrm{mm} \times 1.0-\mu \mathrm{m}$ capillary column (Agilent Technologies Inc., Wilmington, DE), and ChemStation software (Agilent Technologies Inc.) based on methodology from Supelco Inc. (1975). The interassay coefficients of variation for acetate, propionate, isobutyrate, butyrate, isovalerate, valerate, and caproate were 7.7, $7.1,6.8,6.7,13.7,6.9$, and $8.3 \%$, respectively.

Rumen ammonia concentrations were analyzed by the direct enzymatic method (Pesce and Kaplan, 1996) using Infinity Ammonia Liquid Stable Reagent (catalog no. TR60101; Beckman Coulter Australia Pty. Ltd.), on an Olympus AU400 Autoanalyzer (AHL NTM-56; Olympus, Mount Waverly, VIC, Australia). The interassay coefficient of variation for ammonia samples was $10 \%$. Rumen D-lactate was analyzed using a UV method for D-lactate determination in rumen fluid using a Boehringer Mannheim kit (catalog no. 11112821 035; R-Biopharm-Laboratory Diagnostics Pty. Ltd., Taren Point, NSW, Australia) after deproteinization with perchloric acid according to kit instructions on an Olympus AU400 Autoanalyzer. Rumen L-lactate was analyzed using a UV method for L-lactate determination in rumen fluid using a Beckman Coulter kit (catalog no. OSR 6193; Beckman Coulter Australia Pty. Ltd.) on an Olympus AU400 Autoanalyzer.

Rumen histamine concentrations were analyzed in samples collected 5 and 215 min after challenge ration consumption and plasma histamine in those collected 215 min after challenge ration consumption. Analysis was performed within 7 wk of sample collection using a human histamine ELISA kit (catalog no. RE59221; IBL International GmbH, Hamburg, Germany) according to the manufacturer's instructions for human plasma samples (Golder et al., 2012). Rumen fluid was passed through a $0.22-\mu \mathrm{m}$ polyethersulfone membrane syringe filter (Millipore Ireland BV, Carrigtwohill, Co. Cork, Ireland) and diluted 1:2 with assay buffer supplied within the kit before analysis. Absorbance was measured at $450 \mathrm{~nm}$ using a POLARstar Optima microplate reader (BMG Labtech, Melbourne, VIC, Australia). The interassay coefficient of variation was $<17 \%$ and the intraassay coefficient of variation for rumen fluid was $<15 \%$ and $<8 \%$ for plasma.
Plasma reactive oxygen metabolites (dROM; dROMs Test; Diacron International srl, Grosseto, Italy) and biological antioxidant potential (BAP; Bap Test; Diacron International srl) were measured according to kit instructions. The extent of oxidative stress was expressed as an oxidative stress index (OSI), estimated using the ratio of $(\mathrm{dROM} / \mathrm{BAP}) \times 100(\mathrm{Celi}, 2011)$. Plasma ceruloplasmin concentration was determined according to the methods described by Sunderman and Nomoto (1970), with the exception that absorbance was read at $510 \mathrm{~nm}$ (POLARstar Optima; BMG Labtech).

\section{Statistical Analysis}

All data were analyzed using the following linear mixed model in GenStat (14th edition; VSN International Ltd., Hemel Hempstead, UK), unless otherwise indicated:

$$
\mathrm{Y}_{\mathrm{ijkl}}=\mu+\beta_{\mathrm{i}}+\gamma_{\mathrm{j}}+(\beta \gamma)_{\mathrm{ij}}+\mathrm{X}_{\mathrm{k}}+(\mathrm{XZ})_{\mathrm{kl}}+\varepsilon_{\mathrm{ijkl}},
$$

where $Y_{\mathrm{ijkl}}=$ response of group $\mathrm{i}(\mathrm{i}=1$ to 5$)$ at the $\mathrm{jth}$ period ( $\mathrm{j}=1$ to 4 ; or time $\mathrm{j}=1$ to 5 ; or study day $\mathrm{j}=$ 1 to 20 ) from block $\mathrm{k}(\mathrm{k}=\mathrm{A}$ to $\mathrm{D})$ by heifer $\mathrm{l}(\mathrm{l}=1$ to 39$) ; \mu=$ overall mean; $\beta_{\mathrm{i}}=$ fixed effect of treatment group; $\gamma_{j}=$ fixed effect of period (or time); $(\beta \gamma)_{i j}=$ effect of group by period (or time, or study day) interaction; $\mathrm{X}_{\mathrm{k}}=$ random effect of block; $(\mathrm{XZ})_{\mathrm{kl}}=$ random effect of heifer nested within block; and $\varepsilon_{\mathrm{ijkl}}=$ random residual error within heifer 1 at period (or time, or study day) $\mathrm{j}$ from block $\mathrm{k}$. The covariance structure of the random error terms of the model was independent. This model was chosen following examination of other covariance structures, including first-order autoregressive (AR1) structures using a likelihood ratio test to compare models; consequently, all the correlation was modeled through the random terms. A residual analysis was performed for each response variable, testing for the distributional assumption, homogeneity of the variance, and influential observations using residual and deviance plots.

Preadaptation rumen and plasma measures were analyzed without the fixed effect of period and the interaction of group by period (data not shown). The same model was used to test the effect of group for arrival, adaptation I, and challenge BW, and ADG and feed conversion ratio (FCR) from adaptation I to challenge. Arrival BW was used as a covariate for adaptation I and challenge BW. Six BW measurements were rejected as implausible and replaced by points interpolated by calculating the average of the BW taken from the previous and subsequent week, including one arrival BW, estimated by extrapolation using a linear trend line. 
Study day ( $\mathrm{j}=1$ to 20 ) was used as a main effect in replacement of period for the analysis of DMI and ration consumption percentage over the 20-d adaptation. Dry matter intake and ration consumption percentage on challenge day were analyzed without the fixed effect of period and the interaction of group by period. Individual heifer ration consumption percentages within each group were graphed over the 20-d adaptation (data not shown). The difference in ration consumption percentage and DMI between the mean $3 \mathrm{~d}$ before and after challenge was analyzed using the fixed effects of group and period, and their interaction ( $\mathrm{j}=1$ to 2 ; data not shown).

Acidosis risk at the preadaptation and adaptation I and II periods was assessed using eigenvalues based on the statistical distance of each sample from the centroid for known acidosis cases. Eigenvalues approaching close to 1 are in the center of the acidosis category and those approaching 0 are not acidotic. Acidosis eigenvalues were obtained using discriminant analysis and the acidosis categories defined according to the methods of Bramley et al. (2008). Heifers did not classify appropriately using this model for any of the 5 sample times on challenge day. The main effects of group and period $(j$ $=1$ to 3 ) and their interaction for the acidosis eigenvalues were analyzed using the linear model described. No covariates were used.

Weekly rumen and plasma data measured were analyzed using the linear model described. Only measures from the final challenge sampling $(215 \mathrm{~min})$ were used in the data set for the fourth week measurement (d 21). No covariates were significant. The variables rumen valerate and isovalerate were transformed using a logarithm base 10 and rumen acetate to propionate ratio, total lactate, and D- and L-lactate were transformed using a natural log to achieve a normal distribution of residuals.

All rumen and plasma data from the challenge period were analyzed with the fixed effects of group and time, and their interaction. Plasma was obtained at the 5 - and 215-min samplings only ( $\mathrm{j}=1$ to 2 ). The covariates, arrival BW, preadaptation (d 0) measures, mean DMI and ration consumption percentage over the $20-\mathrm{d}$ adaptation, BW at challenge, DMI at challenge, consumption percentage of challenge ration, and time for challenge ration consumption were tested in the model, but none were significant. The variables rumen valerate and isovalerate were transformed using a logarithm base 10 to achieve a normal distribution of residuals. Data from each heifer within each group was graphed over the challenge sampling period to identify heifers with unusual measures (data not shown).

A Pearson correlation was performed to determine the relationship between rumen and plasma histamine concentrations at the final challenge sampling, regardless of group. A count of locomotion scores $\geq 2$ for each group and period was performed and no formal analysis was undertaken for these.

\section{RESULTS}

A heifer from the MT group was removed from the final analysis, as she consumed only $12 \%$ of her challenge ration. No differences in rumen or plasma measures were obtained between groups in the preadaptation sampling (data not shown).

\section{Clinical Observations During Adaptation}

Abnormal watery, bubbly feces were observed for several heifers from different feed additive groups during the 20-d adaptation period. Six heifers (1 control, 1 VM, $3 \mathrm{MT}$, and $1 \mathrm{MLY}$ ), including a heifer later excluded from the study, were given a physical examination on d 4 after presenting with a dull demeanor and inappetence. Rectal temperatures were within the normal range, 2 heifers had elevated heart rates (98 and 100 beats per minute), 1 had a rumen $\mathrm{pH}$ of 5.6 , and 2 had infrequent or no rumen contractions. All 40 heifers were subsequently given access to millet hay with their TMR for the following $3 \mathrm{~d}$. None of these 6 heifers examined showed signs of lameness and resumed normal appetite within 2 to $5 \mathrm{~d}$ after examination.

\section{BW and DMI During Adaptation}

Body weight at adaptation I and challenge, ADG, and FCR were not affected by group (Table 4). Over the 20-d adaptation, DMI was greatest in the VM and BUF groups, similar in the MT and BUF groups, and also similar in the control and MT groups; however, DMI was lowest in the MLY group (Table 4). Heifers had the lowest DMI and percentage of offered ration consumed on study d 3 and 4 and the highest DMI on study d 19 and 20 (Figure 2). Marked variation in ration consumption percentage among heifers within each group was observed but was greatest in the control, MT, and MLY groups. A cyclic feeding pattern was also observed for these groups (Figure 2).

\section{Acidosis Classification}

Acidosis eigenvalues showed a trend toward a group by period interaction $(P=0.09)$ and period effect $(P$ $=0.07 ;$ Table 5). Eigenvalues increased weekly and were greatest for the MT and control groups (Table 5; Figure $3 \mathrm{~A}$ ). Three heifers (2 from the MT and 1 from the control group) were classified as acidotic based on 
Table 4. Predicted means $( \pm \mathrm{SEM})$ of adaptation I and challenge BW, ADG, and feed conversion ratio (FCR) over a 23-d period from adaptation I to challenge; mean DMI and ration consumed over the 20-d adaptation period; and mean DMI, ration consumed, and consumption time on challenge day ${ }^{1}$

\begin{tabular}{|c|c|c|c|c|c|c|c|c|}
\hline \multirow[b]{2}{*}{ Item } & \multicolumn{5}{|c|}{ Group $^{2}$} & \multirow[b]{2}{*}{ SEM } & \multicolumn{2}{|c|}{ Main effect ( $P$-value) } \\
\hline & Control & VM & MT & MLY & BUF & & Group & Study day \\
\hline Adaptation I BW ${ }^{3}(\mathrm{~kg})$ & 388 & 380 & 387 & 383 & 385 & 4.26 & 0.46 & - \\
\hline Challenge $\mathrm{BW}^{3}(\mathrm{~kg})$ & 423 & 418 & 420 & 423 & 426 & 6.31 & 0.80 & - \\
\hline $\mathrm{ADG}(\mathrm{kg} / \mathrm{d})$ & 1.47 & 1.71 & 1.48 & 1.66 & 1.78 & 0.22 & 0.75 & - \\
\hline $\mathrm{DMI}(\mathrm{kg} / \mathrm{d})$ & $9.34^{\mathrm{b}}$ & $10.89^{\mathrm{d}}$ & $9.97^{\mathrm{bc}}$ & $8.49^{\mathrm{a}}$ & $10.17^{\mathrm{cd}}$ & 0.41 & 0.002 & $<0.001$ \\
\hline Ration consumed (\% of offered ration consumed/d) & $90.5^{\mathrm{b}}$ & $95.1^{\mathrm{c}}$ & $80.7^{\mathrm{a}}$ & $82.7^{\mathrm{a}}$ & $92.9^{\mathrm{bc}}$ & 2.02 & $<0.001$ & $<0.001$ \\
\hline \multicolumn{9}{|l|}{ Challenge } \\
\hline DMI $(\mathrm{kg})$ & $4.60^{\mathrm{b}}$ & $5.03^{\mathrm{bc}}$ & $5.54^{\mathrm{c}}$ & $3.27^{\mathrm{a}}$ & $4.70^{\mathrm{b}}$ & 0.41 & 0.007 & - \\
\hline Ration consumed ( $\%$ of offered ration consumed) & $90.8^{\mathrm{b}}$ & $90.5^{\mathrm{b}}$ & $93.1^{\mathrm{b}}$ & $65.0^{\mathrm{a}}$ & $87.8^{\mathrm{b}}$ & 8.05 & 0.03 & - \\
\hline Consumption time $(\min )$ & 59.3 & 49.13 & 57.7 & 80.4 & 68.9 & 8.73 & 0.06 & - \\
\hline
\end{tabular}

${ }^{\mathrm{a}-\mathrm{d}}$ Means within a row not sharing a common superscript differ significantly $(P<0.05)$.

${ }^{1}$ The main effects of group and study day are reported where relevant.

${ }^{2}$ Control $=$ no feed additives; $\mathrm{VM}=$ virginiamycin; $\mathrm{MT}=$ monensin + tylosin; MLY $=$ monensin + live yeast; BUF $=$ sodium bicarbonate + magnesium oxide.

${ }^{3}$ Arrival BW was used as a covariate in the analysis.

${ }^{4}$ When 1 heifer with an FCR of $70.6 \mathrm{~kg}$ of DMI $/ \mathrm{kg}$ of gain was removed from the VM group, the mean FCR was $6.50 \mathrm{~kg}$ of DMI $/ \mathrm{kg}$ of gain.

${ }^{5}$ When 1 heifer with an FCR of $70.6 \mathrm{~kg}$ of DMI/ $\mathrm{kg}$ of gain was removed from the VM group, the $P$-value was 0.39 .

eigenvalues and Bramley et al. (2008) acidosis group classification at the adaptation II sampling.

\section{Weekly Rumen and Plasma Profiles}

Total VFA and acetate concentrations were influenced by the group by period interaction, with concentrations for all groups increasing from the preadaptation to the adaptation I sampling. Concentrations of total VFA and acetate were increased in the BUF group, decreased in the MT group, and were relatively similar to adaptation I concentrations for the other groups at the adaptation II sampling. Concentrations of these decreased for all groups, with the exception of an increase for the MT group at the challenge sampling (Table 5; Figure 3B and C).

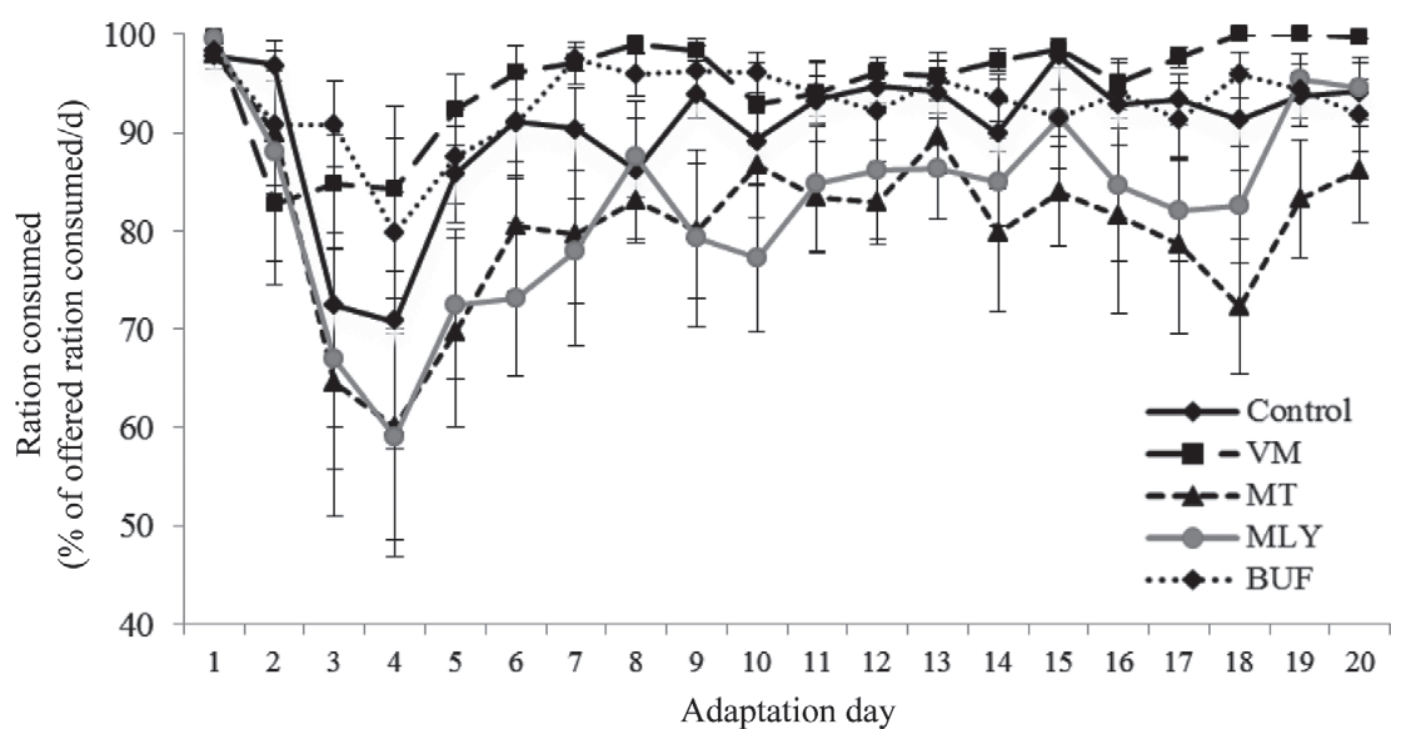

Figure 2. Mean $( \pm \mathrm{SEM})$ percentage of ration consumed for each feed additive group over the 20-d adaptation period. Control $=$ no feed additives; VM = virginiamycin; MT = monensin + tylosin; MLY = monensin + live yeast; BUF = sodium bicarbonate + magnesium oxide. 
Table 5. Main effects ( $P$-values) of group and period and their interaction for acidosis eigenvalues, and rumen and plasma measures taken weekly from preadaptation (d 0) to the final sampling on challenge day (d 21; 215 min after ration consumption; no. of samples $=156 ; 4$ samples $/$ heifer)

\begin{tabular}{|c|c|c|c|}
\hline \multirow[b]{2}{*}{ Item } & \multicolumn{3}{|c|}{$P$-value } \\
\hline & Group (G) & Period $(\mathrm{P})$ & $\mathrm{G} \times \mathrm{P}$ \\
\hline Acidosis eigenvalue $^{1}$ & 0.22 & 0.07 & 0.09 \\
\hline \multicolumn{4}{|l|}{ Rumen $(\mathrm{m} M)$} \\
\hline Total VFA & 0.08 & $<0.001$ & 0.04 \\
\hline Acetate & 0.001 & 0.006 & 0.005 \\
\hline Propionate & 0.23 & $<0.001$ & 0.39 \\
\hline Ln acetate:propionate & 0.003 & $<0.001$ & 0.50 \\
\hline Butyrate & 0.11 & $<0.001$ & 0.38 \\
\hline Isobutyrate & 0.04 & $<0.001$ & 0.34 \\
\hline Caproate & 0.18 & $<0.001$ & 0.009 \\
\hline $\log _{10}$ valerate & 0.35 & $<0.001$ & 0.07 \\
\hline $\log _{10}$ isovalerate & 0.22 & $<0.001$ & 0.01 \\
\hline Ln total lactate & 0.08 & $<0.001$ & 0.31 \\
\hline Ln D-lactate & 0.07 & $<0.001$ & 0.18 \\
\hline Ln L-lactate & 0.04 & $<0.001$ & 0.22 \\
\hline Ammonia & 0.14 & $<0.001$ & 0.20 \\
\hline $\mathrm{pH}$ & 0.12 & $<0.001$ & 0.10 \\
\hline \multicolumn{4}{|l|}{ Plasma $^{2}$} \\
\hline dROM (Carr. U) & 0.33 & $<0.001$ & 0.11 \\
\hline $\mathrm{BAP}(\mu M)$ & 0.43 & $<0.001$ & 0.65 \\
\hline OSI (arbitrary units) & 0.65 & $<0.001$ & 0.24 \\
\hline Ceruloplasmin (mg/L) & 0.97 & 0.03 & 0.83 \\
\hline
\end{tabular}

Propionate concentrations increased between the preadaptation and adaptation I sampling, concentrations were relatively consistent between the adaptation I and II sampling, and decreased at the challenge sampling (Table 5; Figure 3D). The acetate-to-propionate ratio decreased between the preadaptation and adaptation I sampling and was relatively stable between the adaptation I and challenge samplings. The ratio increased in the BUF group at the challenge sampling (Table 5; Figure 3E). Butyrate concentrations increased for the majority of groups (Table 5; Figure 3F). Isobutyrate concentrations decreased for all groups from preadaptation to adaptation I and increased between adaptation I and II, except for a decrease in the MT group, before decreasing in all groups at the challenge sampling.

Caproate and valerate concentrations increased weekly (Table 5; Figure 3G). Isovalerate concentrations increased, except in the BUF group, from preadaptation to adaptation I, decreased in the VM and MT groups, and increased in the other groups between adaptation I and II. Isovalerate concentrations decreased in the MLY, control, and VM groups and remained relatively stable for the other groups between adaptation II and challenge (Table 4).

Total lactate concentrations increased from a mean of $0.09 \pm 0.05$ to $25.4 \pm 7.0 \mathrm{~m} M$ from preadaptation to challenge day (Table 5; Figure 3H). D-Lactate and L- lactate concentrations increased markedly at challenge day (Table 5; Figure 3I and J, respectively). L-Lactate concentrations were highest in the control group.

Ammonia concentrations decreased between the preadaptation and adaptation I sampling, increased in the majority of groups at the adaptation II sampling, and decreased on challenge day (Table 5; Figure 3K). Rumen $\mathrm{pH}$ was not different between groups but was highest at the preadaptation sampling, lower at adaptation I, increased at adaptation II, and was the lowest at challenge sampling: 0.81 units lower than at preadaptation (Table 5; Figure 3L).

Plasma dROM, BAP, OSI, and ceruloplasmin concentrations were not influenced by the group by period interaction or group effect (Table 5). The concentration of dROM was similar at the preadaptation and challenge day, but increased between the preadaptation to adaptation I, and the adaptation I to adaptation II samplings (Table 5; Figure 4A). The BAP concentrations were consistent at the preadaptation and challenge day samplings but were increased between these periods (Table 5; Figure 4B). The OSI was highest at the adaptation II sampling (Table 5; Figure 4C). Ceruloplasmin concentrations peaked at the adaptation I sampling and returned to a concentration comparable to that at preadaptation by the challenge sampling (Table 5; Figure 4D). 

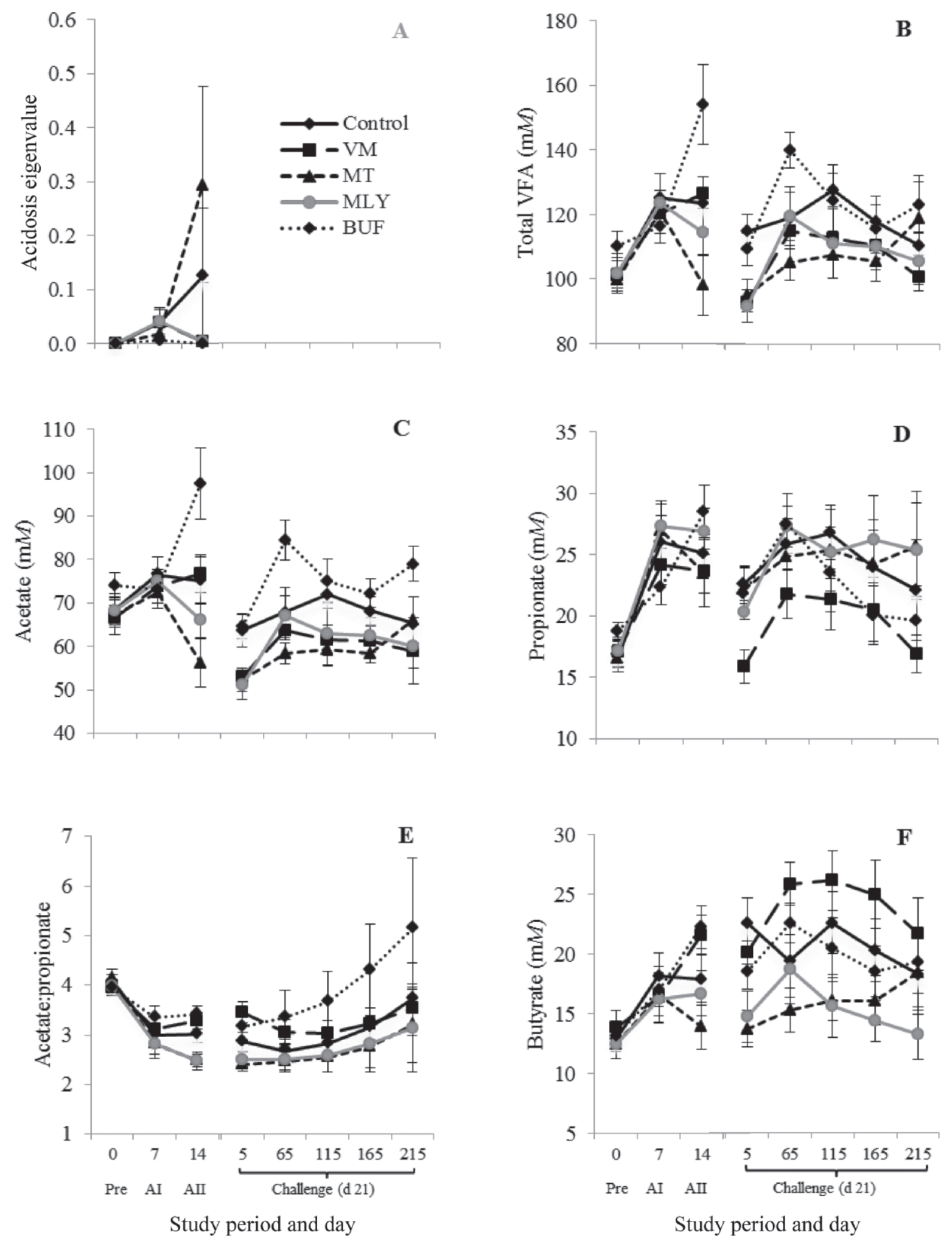

Study period and day

Figure 3. Mean $( \pm$ SEM) acidosis eigenvalue $(0=$ not acidotic to $1=$ acidosis; A), rumen total VFA (B), acetate $(\mathrm{C})$, propionate $(\mathrm{D})$, acetate:propionate ratio $(\mathrm{E})$, butyrate $(\mathrm{F})$, valerate $(\mathrm{G})$, total lactate $(\mathrm{H})$, D-lactate $(\mathrm{I})$, L-lactate $(\mathrm{J})$, ammonia $(\mathrm{K})$, and rumen pH $(\mathrm{L})$ measures for feed additive groups collected during the 4 experimental periods on the study day in parentheses: Pre $=$ preadaptation $(\mathrm{d} 0)$, AI $=$ adaptation I (d 7), AII = adaptation II (d 14), and challenge day (d 21). On the challenge day, rumen fluid samples were collected 5, 65, 115, 165, and 215 min after challenge ration consumption. Control $=$ no feed additives; $\mathrm{VM}=$ virginiamycin; $\mathrm{MT}=$ monensin + tylosin; $\mathrm{MLY}=$ monensin + live yeast; $\mathrm{BUF}=$ sodium bicarbonate + magnesium oxide. 

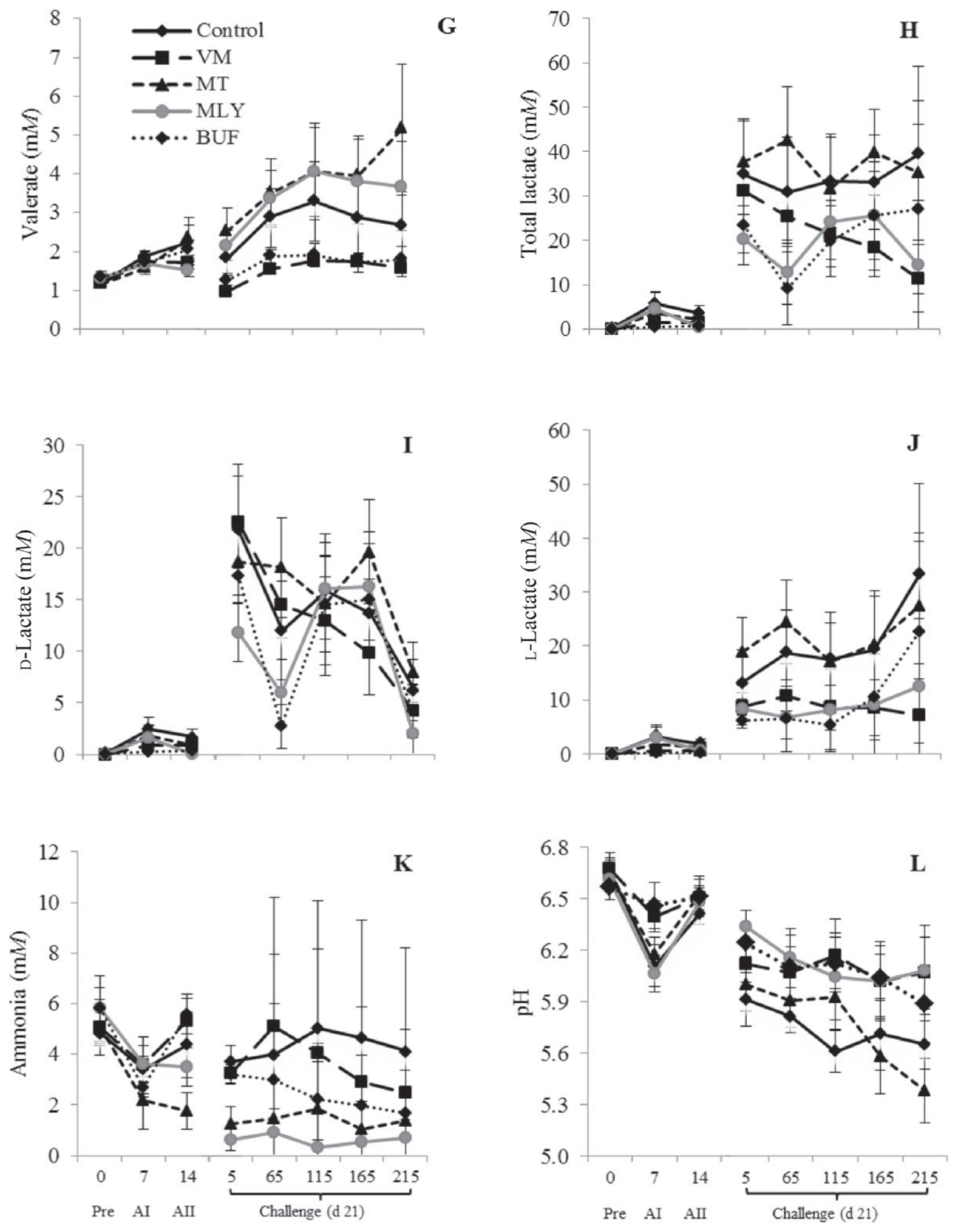

Study period and day

Study period and day

Figure 3 (Continued). Mean $( \pm \mathrm{SEM})$ acidosis eigenvalue $(0=$ not acidotic to 1 = acidosis; $\mathrm{A})$, rumen total VFA (B), acetate $(\mathrm{C})$, propionate $(\mathrm{D})$, acetate:propionate ratio $(\mathrm{E})$, butyrate $(\mathrm{F})$, valerate $(\mathrm{G})$, total lactate $(\mathrm{H})$, D-lactate $(\mathrm{I})$, L-lactate $(\mathrm{J})$, ammonia $(\mathrm{K})$, and rumen $\mathrm{pH}$ (L) measures for feed additive groups collected during the 4 experimental periods on the study day in parentheses: Pre $=$ preadaptation $(\mathrm{d} 0)$, $\mathrm{AI}=$ adaptation I (d 7), AII = adaptation II (d 14), and challenge day (d 21). On the challenge day, rumen fluid samples were collected 5, 65, 115, 165, and 215 min after challenge ration consumption. Control $=$ no feed additives; $\mathrm{VM}=$ virginiamycin; $\mathrm{MT}=\mathrm{monensin}+$ tylosin; $\mathrm{MLY}$ $=$ monensin + live yeast BUF $=$ sodium bicarbonate + magnesium oxide. 

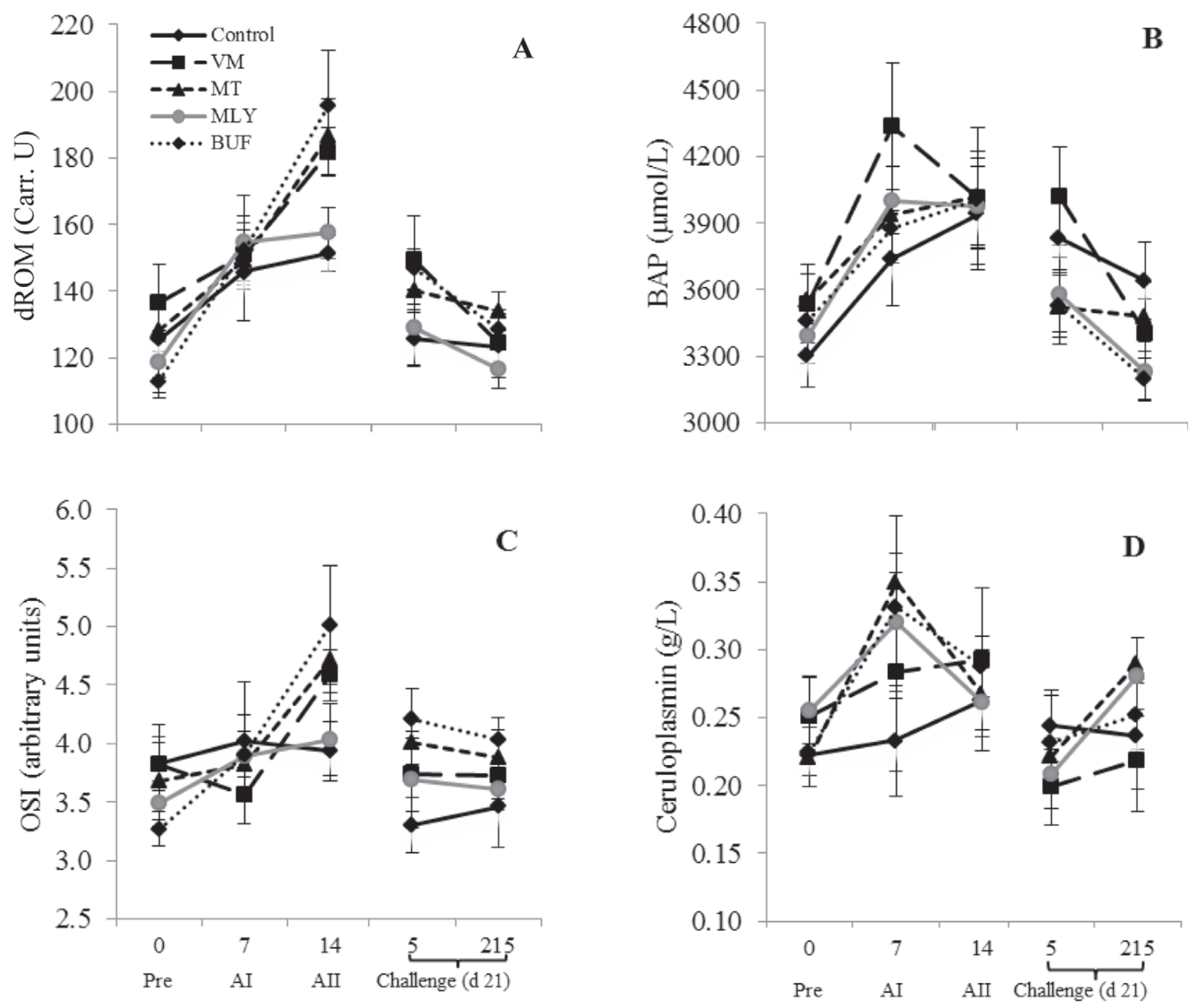

Study period and day

Study period and day

Figure 4. Mean $( \pm$ SEM) measures of plasma reactive oxygen metabolites (dROM; A); biological antioxidant potential (BAP; B); oxidative stress index (OSI; C), and ceruloplasmin (D) measures for feed additive groups collected during the 4 experimental periods on the study day in parentheses: Pre = preadaptation (d 0), AI = adaptation I (d 7), AII = adaptation II (d 14), and challenge day (d 21). On the challenge day, blood was collected 5 and 215 min after challenge ration consumption. Control $=$ no feed additives; $\mathrm{VM}=$ virginiamycin; $\mathrm{MT}=$ monensin + tylosin; MLY = monensin + live yeast; $\mathrm{BUF}=$ sodium bicarbonate + magnesium oxide; Carr. $\mathrm{U}=\mathrm{Carratelli}$ units $(1 \mathrm{Carr} . \mathrm{U}=0.08 \mathrm{mg} / 100$ $\mathrm{mL}$ of hydrogen peroxide).

\section{Clinical Signs and DMI on Challenge Day}

No clinical signs of acidosis were observed during the sampling period. A control heifer in the first block of heifers challenged was diagnosed with acute ruminal acidosis $10 \mathrm{~h}$ after challenge feeding. She was drenched with $200 \mathrm{~g}$ of sodium bicarbonate in $20 \mathrm{~L}$ of water 24 $\mathrm{h}$ after challenge and had recovered by $48 \mathrm{~h}$ after chal- lenge. A detailed clinical case report on this heifer will be available (Golder et al., 2013a).

Dry matter intake was greatest for the MT and VM heifers and lowest for the MLY heifers, which, on average, consumed only $65 \%$ of their offered ration (Table 4). Ration consumption time approached significance $(P=0.06)$, with VM heifers, on average, consuming the ration the quickest (approximately $49 \mathrm{~min}$ ), compared 
with the BUF heifers, which took approximately 20 min longer (Table 4). No difference was observed in percentage of ration consumption and DMI $3 \mathrm{~d}$ before and after challenge $(P=0.72$ and $P=0.83$, respectively; data not shown).

\section{Rumen and Plasma Profiles on Challenge Day}

Caproate was the only rumen measure with a group by time interaction (Table 6). Acetate concentrations were highest in the BUF group and also high in the controls. Acetate concentrations were similar in the VM, MT, and MLY groups. Acetate concentrations increased between the 5- and 65-min sampling and then plateaued (Table 6; Figure 3C). Butyrate concentrations were higher in the control and BUF groups compared with the MT and MLY groups (Table 6; Figure $3 \mathrm{~F})$. Butyrate concentrations were highest between the 65- to 165-min samplings and returned to concentrations similar to those at the initial sampling by $215 \mathrm{~min}$ (Figure $3 \mathrm{~F}$ ). Valerate concentrations were lowest in the VM and BUF groups and highest in the MT and MLY groups. Valerate concentrations for the control were similar to all other groups. Valerate concentrations increased between the 5- and 65-min sampling times and then plateaued (Table 6; Figure 3G). Ammonia concentrations were lowest in the MLY and MT groups. The MT and BUF groups had a comparable ammonia concentration, as did the BUF and VM, and VM and control groups. Ammonia concentrations were highest at the 65-min sampling (Table 6; Figure 3K).

No group effects were evident for rumen total or other individual VFA, lactate, or $\mathrm{pH}$ measures; however, time effects were significant for each of these measures, with the exception of total lactate. Total VFA, propionate, and L-lactate concentrations increased between the 5and 65-min sampling times and then plateaued (Table 6 ; Figure 3B, D, and J). The acetate-to-propionate ratio was highest at the final sampling (215 min; Figure $3 \mathrm{E})$. D-Lactate concentration decreased at the 65-min sampling, returned to a concentration similar to that at the first sampling over the 115- to 165 -min period, and decreased at the final 215-min sampling (Table 6 ; Figure 3I). Rumen $\mathrm{pH}$ decreased after the 115-min sampling (Figure 3L).

Rumen histamine concentrations were considerably lower in the MLY heifers compared with other groups and more than 4-fold lower than those of the VM group.

Table 6. Predicted means $( \pm \mathrm{SEM})$, main effects of group and time, and their interaction for rumen measures taken $5,65,115,165$, and 215 min and plasma measures taken 5 and 215 min after consumption of respective challenge ration

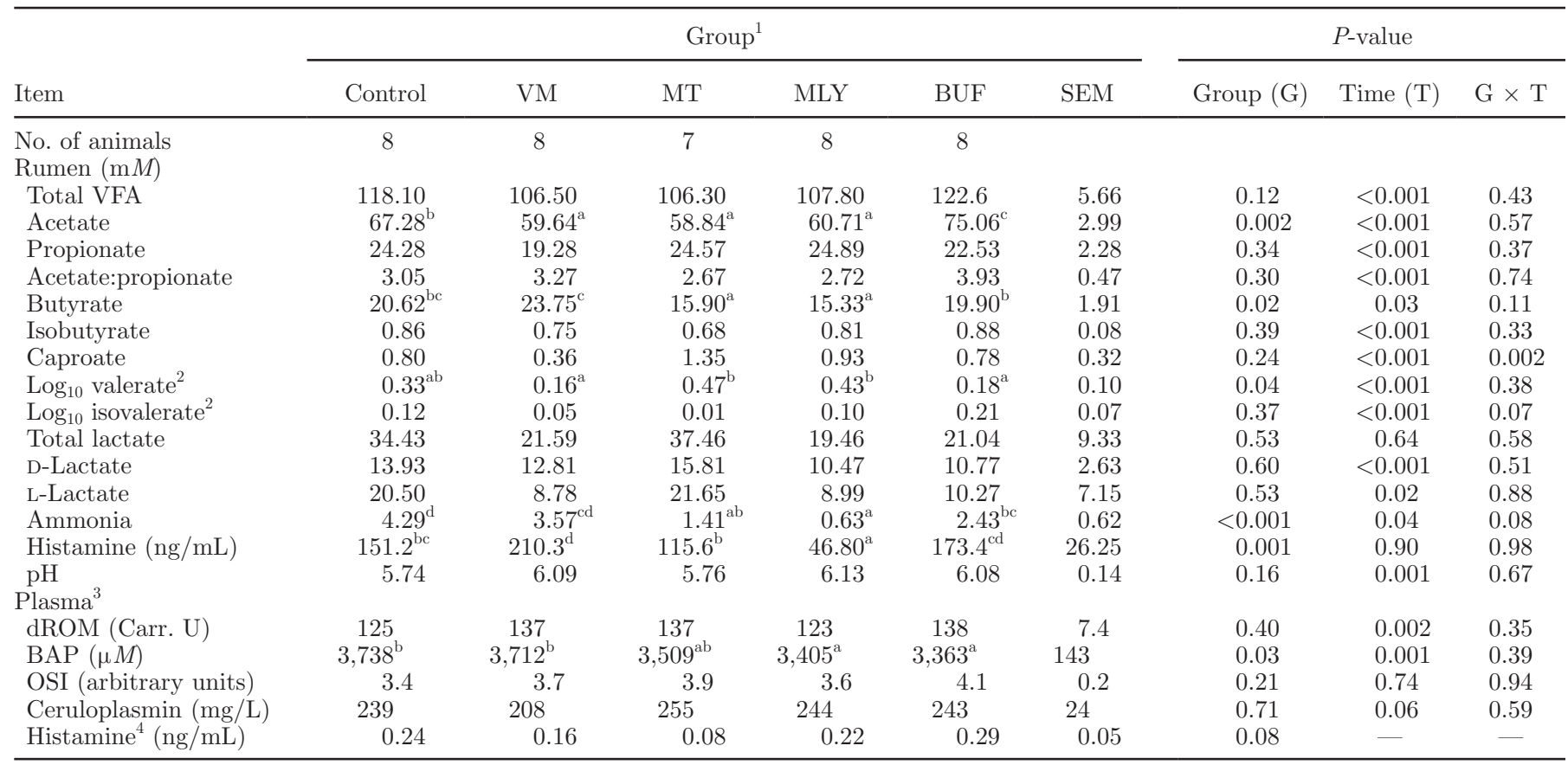

\footnotetext{
${ }^{\mathrm{a}-\mathrm{d}}$ Means within a row not sharing a common superscript differ significantly $(P<0.05)$.

${ }^{1}$ Control $=$ no feed additives; $\mathrm{VM}=$ virginiamycin; $\mathrm{MT}=$ monensin + tylosin; $\mathrm{MLY}=$ monensin + live yeast; BUF $=$ sodium bicarbonate + magnesium oxide; BAP = biological antioxidant potential.

${ }^{2} \log ^{-1}(\mathrm{y})$ of $\log _{10}$ valerate: $2.14,1.45,2.95,2.69$, and $1.51 ; \log _{10}$ isovalerate: $1.32,1.12,1.02,1.26$, and 1.62 .

${ }^{3} \mathrm{dROM}=$ reactive oxygen metabolites; Carr. $\mathrm{U}=$ Carratelli units $(1$ Carr. $\mathrm{U}=0.08 \mathrm{mg} / 100 \mathrm{~mL}$ of hydrogen peroxide); BAP $=$ biological antioxidant potential; OSI $=$ oxidative stress index $[(\mathrm{dROM} / \mathrm{BAP}) \times 100]$.

${ }^{4}$ Histamine was reported for the 215-min sample collection only.
} 
998

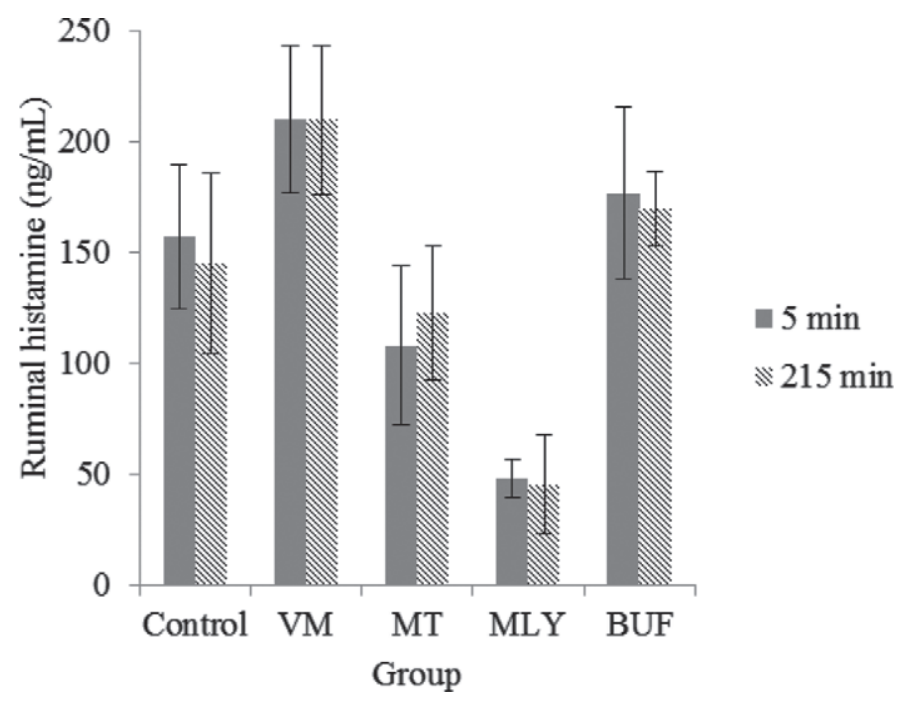

Figure 5. Mean $( \pm \mathrm{SEM})$ rumen histamine concentration for feed additive groups from rumen fluid collected 5 and 215 min after consumption of the challenge ration. Control $=$ no feed additives; $\mathrm{VM}=$ virginiamycin; $\mathrm{MT}=$ monensin + tylosin; $\mathrm{MLY}=$ monensin + live yeast; $\mathrm{BUF}=$ sodium bicarbonate + magnesium oxide.

The VM and BUF, BUF and control, and control and MT groups had comparable concentrations (Table 6; Figure 5). Rumen and plasma histamine concentrations were not correlated $(\mathrm{r}=-0.07)$.

The concentration of BAP decreased over the challenge sampling and was similar in the control, VM, and MT groups. Concentrations were lower in the MLY and BUF groups, which were comparable to that of the MT cattle (Table 6; Figure 4B). Concentrations of dROM, OSI, ceruloplasmin, and histamine in plasma were not affected by the interaction of group by time or the main effect of group (Table 6; Figure 4A, C, and D). Concentrations of dROM decreased over the challenge sampling (Figure 4A) and a trend occurred toward an increase in ceruloplasmin concentrations $(P$ $=0.06$; Table 6 ; Figure 4D).

The relatively large standard errors of the mean in Table 6 and error bars in Figure 3 indicate considerable between-heifer variation within all groups. For example, within the VM group, 2 heifers had considerably lower rumen $\mathrm{pH}$ and higher propionate and lactate concentrations than the other 6 . One heifer's rumen $\mathrm{pH}$ decreased from 5.9 to 5.1 and propionate concentration increased from 23 to $36 \mathrm{mM}$ between the 5 - and 165-min samplings and her total lactate concentration peaked at $60 \mathrm{~m} M$ (65-min sampling). Similarly, in the MLY group, a heifer had a rumen $\mathrm{pH}$ of 6.1 that decreased to 4.6 and total lactate and ammonia concentrations that increased from 25 to 116 and 0.2 to $5.7 \mathrm{mM}$, respectively, over the challenge sampling. Her acetate concentration was higher until the 115-min sampling, whereafter it and propionate and butyrate concentrations dropped. One heifer from the BUF group had a rumen $\mathrm{pH}$ that decreased to 4.8 and a total lactate concentration of $148 \mathrm{~m} M$ at the final sampling.

\section{Locomotion Scores}

Of the total number of locomotion scores taken on 7 occasions throughout the study, only $4.8 \%$ had a score $\geq 2$ and no scores were above 2.5 . No difference in locomotion scores occurred between groups; however, no scores $\geq 2$ were recorded in the preadaptation or 5 -d-after-challenge scoring sessions.

\section{DISCUSSION}

The starch and fructose challenge model was sufficient to evaluate the capacity of feed additives to reduce ruminal acidosis risk, given the substantial changes in rumen conditions during the adaptation period and over the first 215 min after the challenge feed. Cyclic feeding patterns and clinical signs of acidosis in some heifers during the adaptation period and diagnosis of a clinical case of acute ruminal acidosis on challenge day further validates the severity of this challenge model.

None of the feed additives examined stabilized the rumen in all the heifers; however, positive responses to interventions were evident in all groups. The complex interactions within the rumen ecosystem and differences in modes of action of the feed additives are evident in the diverse responses of individuals within groups.

The challenge ration fed at $1.2 \%$ of $\mathrm{BW}$ is similar to the challenge rations of Golder et al. (2012) and Lean et al. (2013) fed to dairy heifers. Grain-based rations up to $1.5 \%$ of $\mathrm{BW}$ or diets that contained glucose at 0.3 to $0.6 \%$ of BW produced subacute ruminal acidosis with minimal risk of acute ruminal acidosis (Nagaraja and Titgemeyer, 2007). Ruminal and systemic acidosis has been induced in dairy heifers of comparable ages and weights to those in this study by orally drenching with oligofructose at $0.17 \%$ of BW (Danscher et al., 2010). The TMR fed in the adaptation II period (NDF at 33.6 , starch at $26.4, \mathrm{NFC}$ at 47.7 , and sugar at $12.6 \%$ of $\mathrm{DM})$ is representative of beef feedlot rations and some lactating dairy rations and thus should mirror effects in the field. Average daily gains were much higher than expected and consistent with those of feedlot cattle (Reinhardt et al., 2012), providing additional validation of the performance of the diets.

The challenge was large enough to induce a prooxidative response over the duration of the study, but not between groups, a finding consistent with another starch and fructose challenge (Golder et al., 2013b). The effects of period and time on oxidative stress bio- 
markers support the finding by Gabai et al. (2004) that substrate changes influence oxidative stress.

Intake control and subsequent maintenance of optimum rumen conditions may be a defense mechanism of animals or response to feed additives that prevent acidosis (Owens et al., 1998). The quantitative review of Nagaraja and Titgemeyer (2007) suggests that responses in cattle that consume feed appear to be different to those that receive direct rumen challenges such as drenching or insertion of feed using fistulae. These observations support the decision to allow voluntary diet intake, which more closely mimics on-farm practices and ensures that diets are within physiological limits that cattle can consume.

Acidosis definitions have largely been based on various rumen $\mathrm{pH}$ cut points (Gozho et al., 2006; Plaizier et al., 2008); however, $\mathrm{pH}$ determinations vary according to heterogeneity of the rumen, rumen fluid collection method, collection site, intake of fermentable carbohydrate, buffering capacity, rates of absorption, time of day, and the time between feeding and fluid collection (Duffield et al., 2004; Nagaraja and Titgemeyer, 2007; Shen et al., 2012). Saliva contamination may occur when rumen fluid is collected by a stomach tube (Duffield et al., 2004); however, this can be overcome by correct insertion technique (Lodge-Ivey et al., 2009; Shen et al., 2012). It was our intention to define acidosis status based on a combination of standardized individual VFA, ammonia, rumen $\mathrm{pH}$, and lactate measures using the model by Bramley et al. (2008). The trend toward an increase in acidosis risk between the preadaptation and adaptation II samplings, as indicated by the acidosis eigenvalues, was anticipated due to the diet composition.

Rumen fluid measures from the majority of rumen samples collected from all heifers at all 5 sampling times on challenge day were not consistent with the Bramley et al. (2008) model or those from other studies fitted using this model (O'Grady et al., 2008; Golder et al., 2012; Lean et al., 2013). The model was based on rumen measures collected from 800 cows from 100 dairy herds across South Eastern Australia that included predominately pasture-based herds, herds fed grain twice daily at milking, and lot fed herds (Bramley et al., 2008). Approximately $10 \%$ of these cattle were defined as acidotic and the majority of cows in that data set (Bramley et al., 2008) had lactate concentrations $<1$ $\mathrm{m} M$. The high total lactate concentrations of $>19 \mathrm{mM}$ for the mean of each feed additive group on challenge day in our study and individual heifers with concentrations as high as $148 \mathrm{~m} M$ may explain why the samples did not fit the model.

The rumen measures from the challenge day do not consistently fit within any of the definitions used for cattle with normal rumen conditions or cattle with subacute or acute ruminal acidosis (Nordlund and Garrett, 1994; Kleen et al., 2003; Nagaraja and Titgemeyer, 2007). Rumen $\mathrm{pH}$ values were greater than those suggested for cattle with subacute or acute ruminal acidosis by those authors, and lactate concentrations were greater than those suggested for normal cattle. The inability to fit rumen measures to the model of Bramley et al. (2008) or consistently diagnose acidosis in these heifers using current definitions of acidosis based on starch feeding indicates that these heifers had distinctly different rumen profiles to these descriptions. We consider that the majority of heifers in the current study, regardless of feed additive group, experienced lactic acidosis throughout sampling on challenge day, possibly as a result of the fructose inclusion in the diet.

Large increases in lactate have previously only been associated with acute ruminal acidosis (Burrin and Britton, 1986; Nagaraja and Titgemeyer, 2007). Mean total lactate concentrations per group exceeded those $(0$ to $5 \mathrm{mM}$ ) defined by Nagaraja and Titgemeyer (2007) for normal cattle or those with subacute ruminal acidosis for all heifers throughout the challenge sampling, regardless of feed-additive group. However, these were less than concentrations defined by those authors for acute ruminal acidosis (50 to $120 \mathrm{mM}$ ). This suggests that lactate accumulation can occur without clinical signs of acidosis, is not necessarily associated with clinical acidosis severity, and could be associated with dietary substrate.

Differences in bacterial communities may be responsible for the approximately equal proportions of lactate stereoisomers in the VM, MLY, and BUF heifers, and dominant L-lactate concentrations in the control and MT groups. However, the ratio of stereoisomers does not always reflect their production, as lactate racemase can interconvert stereoisomers (Asanuma and Hino, 2002). D-Lactate is metabolized more slowly and has been suggested to be associated with more severe acidosis than L-lactate (Dunlop and Hammond, 1965). Further research on the association between lactate stereoisomers and clinical acidosis is warranted.

Substrates and the length of exposure to substrate influence the risk of acidosis, primarily through changes in microbial communities and rumen papillae (Dirksen et al., 1985; Nagaraja and Titgemeyer, 2007). The current study supports a quantitative review (Nagaraja and Titgemeyer, 2007) that suggests that substrates, particularly sugars, may be a greater risk factor for acidosis than length of substrate exposure, because lactate accumulation occurred on challenge day irrespective of feed additive. In acidosis challenge models, approximately half the amount of glucose compared with grain is required to induce acidosis (Nagaraja 
and Titgemeyer, 2007). Higher lactic acid concentrations were found in direct comparisons between steers fed sugar or starch (Harmon et al., 1985; Heldt et al., 1999) and ruminal and systemic acidosis developed in cattle orally drenched with oligofructose after previous oligofructose exposure (Danscher et al., 2010). A single feed of dietary fructose included at $0.4 \%$ of BW combined with triticale at $0.8 \%$ of $\mathrm{BW}$ increased D-lactate concentrations approximately 22 and 5 fold above control or triticale only-fed heifers, respectively (Golder et al., 2012). These studies suggest that sugars produce higher amounts of lactic acid, pose a greater risk of acidosis than grain-based diets, and that the rumen is more capable of withstanding single starch-based grain exposures compared with exposure to sugars. Substrate may also influence the efficacy of feed additives, an observation that merits further investigation.

Relatively large variations in rumen profile were observed among individual heifers both within and between groups, consistent with some other carbohydrate feeding studies and may reflect the capacity of individuals to utilize different substrates and cope with changes in diet (Brown et al., 2000; Bevans et al., 2005). However, variations are greater than observed in other carbohydrate feeding studies (Mutsvangwa et al., 2002; Golder et al., 2012). These observations emphasize the need for large numbers of experimental animals to test interventions (Nagaraja and Titgemeyer, 2007). The large variation in response can mask the effect of dietary manipulation (Yang and Russell, 1993), and may explain the lack of significant group effects on total VFA, propionate, lactate, and rumen $\mathrm{pH}$ measures that are commonly associated with acidosis (Coe et al., 1999). Despite the large observed among- and withingroup variation in rumen profiles, group differences in rumen acetate, butyrate, valerate, ammonia, and histamine concentrations were evident.

Virginiamycin findings appeared to support the conclusion of Coe et al. (1999) that VM has the potential to moderate rumen fermentation in situations that could lead to rapid production of lactic acid. Responses observed in our study were consistent with VM studies in Holstein steers (Coe et al., 1999), and dairy cattle (Clayton et al., 1999). The combination of increased DMI over the adaptation periods, increased butyrate and ammonia, lower acetate and valerate, and numerically lower propionate and total lactate concentrations, and numerically higher rumen $\mathrm{pH}$ in $\mathrm{VM}$ heifers at challenge samplings supports a role for VM in stabilizing fermentation.

Other cattle studies with VM found similar effects on the proportion of total VFA (Salinas-Chavira et al., 2009) and propionate (Clayton et al., 1999; Valentine et al., 2000) to concentration results to our study. How- ever, numerically lower propionate concentrations in the VM heifers possibly conflict with the proposal that VM selects for propionate-producing bacteria (Dennis et al., 1981). The low valerate concentrations have not been observed in other VM studies (Nagaraja et al., 1987; Valentine et al., 2000).

The numerically lower total lactate concentrations, compared with control heifers, support a proposed mode of action for VM through inhibition of protein synthesis in gram-positive bacteria (Cocito, 1979) and observations of reduced or no effect on rumen lactate concentrations in Holstein steers fed VM (Coe et al., 1999; Salinas-Chavira et al., 2009). However, total lactate concentrations, regardless of group, were abnormally high throughout the challenge sampling, suggesting a degree of acidosis risk and a reduction, but not complete prevention, of lactate accumulation in the VM heifers.

The lack of difference in ammonia concentrations between the VM and control cattle is consistent with other cattle studies (Hedde et al., 1980; Coe et al., 1999; Ives et al., 2002); however, the decrease in ammonia concentrations over the challenge sampling in the VM heifers could support a protein-sparing effect of VM identified in vitro (Van Nevel et al., 1984). The highest histamine concentrations in the VM heifers suggest that VM favors histamine-producing bacteria. The lack of significant effect of VM on rumen $\mathrm{pH}$ is consistent with some findings (Salinas-Chavira et al., 2009) but contrasts with increases (Hedde et al., 1980; Coe et al., 1999) in Holstein steers fed VM.

Clinical observations, the highest acidosis eigenvalues, and variable DMI in the MT group before challenge day suggest these heifers had the greatest acidosis risk before challenge day. On challenge day, similar rumen $\mathrm{pH}$ values to the controls, numerically lowest acetate-to-propionate ratio, and numerically highest lactate concentration suggest that a degree of acidosis risk occurred in the MT group. However, this group appeared to have beneficial effects of lower rumen ammonia and histamine accumulation and increased valerate concentration.

The lack of effect of MT on total VFA concentration is not consistent with an increase (Lean et al., 2000) or decrease (Ives et al., 2002) observed in other MT cattle studies. The absence of effect of MT on propionate concentration is consistent with the majority of MT cattle studies (Morris et al., 1990; Clary et al., 1993); however, it is in contrast to its proposed mode of action of increasing propionate production. The reduction in acetate and butyrate concentrations in both monensin-containing groups is consistent with monensin's proposed mode of action, which may also include a possible reduction in protozoal populations (Poos et 
al., 1979). The highest valerate concentrations in both the monensin groups could indicate growth of bacteria, such as Megasphaera elsdenii, that can ferment lactate to valerate among other end products (Marounek et al., 1989). Valerate is a safe sink for electrons and high concentrations may indicate a lower acidosis risk. Valerate concentration also tended to be higher than controls in MT-fed lactating dairy cattle (Lean et al., 2000).

The low ammonia concentrations in both monensin groups are consistent with the protein-sparing effect and decreased ammonia concentrations reported in monensin-fed dairy cattle (Plaizier et al., 2000; Ghorbani et al., 2011) but no effects have also been observed (Ramanzin et al., 1997; da Silva-Kazama et al., 2011). Protein sparing can be beneficial to the host; however, as ammonia is required for microbial protein synthesis, a very low ammonia concentration could be detrimental, depending on the quality of protein spared.

The lowest concentrations of rumen histamine in both monensin-containing groups may be a positive response to the feed challenge. However, the role of histamine in ruminal acidosis and its sequelae remains unclear despite its well-known vasoactive characteristics. $\mathrm{Ru}-$ men $\mathrm{pH}$ was not influenced by MT in the current study, consistent with findings in feedlot steers (Morris et al., 1990; Clary et al., 1993) but was increased in other MT feedlot studies (Coe et al., 1999; Ives et al., 2002).

The MLY combination showed potential to reduce acidosis risk, largely through reduced rumen acetate, butyrate, and histamine accumulation, higher valerate concentrations, and protein sparing. The low DMI and marked variation in DMI for MLY heifers throughout this study suggest that MLY was not as effective as VM or BUF. Reduced voluntary feed intake could be a strategy to maintain rumen health and did not appear to influence ADG or FCR. In contrast to the current study, no effects on DMI occurred in monensin-fed dairy cattle (Ramanzin et al., 1997; Mutsvangwa et al., 2002) or Levucell SC-fed dairy cattle in a multi-study analysis (de Ondarza et al., 2010), suggesting that the combination of MLY may behave differently than monensin or Levucell SC only.

Consistent with this study, Kowalik et al. (2012) reported no influence of MLY supplementation on total VFA concentrations in Levucell SC-supplemented dairy cattle; however, Želvyte et al. (2006) found that total VFA concentration increased in Levucell SC-fed dairy cattle. Contrary to the increase in acetate concentration in MLY heifers in our study, acetate concentrations were unchanged in Levucell SC-supplemented dairy cattle (Thrune et al., 2009; Kowalik et al., 2012). The increase in butyrate concentration is consistent with that observed in dairy cattle fed Levucell SC (Thrune et al., 2009). Lactic acid concentrations have not been reported in dairy cattle fed Levucell SC and we propose that enhanced growth of lactate-utilizing bacteria may have led to increased movement of electrons to the safe sinks, propionate and valerate. All but one MLY heifer in our study had markedly lower lactate concentrations than the majority of other cattle and concentrations were approximately half those of the MT or control group during challenge (Table 6).

Ammonia concentrations were not affected in dairy cattle fed Levucell SC (Thrune et al., 2009), in contrast to the decrease observed in this study. The numerically highest rumen $\mathrm{pH}$ in the MLY group is consistent with increased rumen $\mathrm{pH}$ in dairy cows supplemented with Levucell SC (Želvytė et al., 2006; Thrune et al., 2009; Kowalik et al., 2012) and lower feed intake. Overall, aspects of response to MLY exist that differ markedly from monensin or Levucell SC fed singly, suggesting a positive synergy.

In the BUF group, feed intake variation was reduced before challenge day and the rumen was stabilized on challenge day; however, the administered recommended inclusion rate of sodium bicarbonate and magnesium oxide was higher than rates fed in practice (Bramley et al., 2012). The increase in DMI before challenge day in the BUF-fed heifers contrasts with effects from quantitative reviews on sodium bicarbonate, magnesium oxide, and their combination (Erdman, 1988; Staples and Lough, 1989; Hu and Murphy, 2005). The majority of studies included in these reviews fed maize silage, which influenced results (Erdman, 1988) and emphasizes the importance of substrate in evaluating studies.

Consistent with our study, propionate and acetate-topropionate ratio were not affected when maize was not included in the ration, except when $>30 \%$ forage diets were fed (Erdman, 1988; Hu and Murphy, 2005). A lack of effect of sodium bicarbonate or magnesium oxide on acetate proportion identified in reviews (Staples and Lough, 1989; Hu and Murphy, 2005) differs from the large increase in acetate in the BUF group. The lack of difference in butyrate concentrations between the BUF and control heifers is similar to the absence of effect on butyrate proportions observed in other BUF dairy cattle studies (Stokes et al., 1986; Arambel et al., 1988). The low valerate concentrations in the BUF heifers may reflect the numerically lower lactate concentrations than controls; however, other studies found no changes in valerate proportion in BUF-fed dairy cattle (Stokes et al., 1986; Arambel et al., 1988).

The lack of rumen $\mathrm{pH}$ difference to controls for the BUF group is consistent with quantitative reviews (Erdman, 1988; Hu and Murphy, 2005); however, the $\mathrm{pH}$ was numerically increased in the majority of studies reviewed by Staples and Lough (1989) and lower for those that fed maize diets (Hu and Murphy, 2005). 
Lactate concentrations were not effected in the BUFfed heifers, consistent with sodium bicarbonate-fed dairy cattle (Kilmer et al., 1981; Kennelly et al., 1999), but were numerically lower than the control and MT groups. The decrease in ammonia concentration may suggest the BUF reduced protein degradation; however, ammonia concentrations were not affected in sodium bicarbonate-fed cattle (Solorzano et al., 1989; González et al., 2008).

\section{CONCLUSIONS}

In summary, our hypothesis that feed additives would reduce acidosis risk compared with unsupplemented control cattle was equivocally supported. All feed additives modified the rumen in ways that influence the risk of acidosis by different means. Some positive and negative rumen fermentation responses to feed additive groups were evident, and no individual group was able to maintain completely favorable ruminal conditions in all heifers. The large variation between animals suggests that feed additives may not be capable of controlling acidosis under extreme challenge or in cattle with a high acidosis risk. Feeding behavior may be an important means by which cattle reduce the risk of acidosis. Metagenomic assessment of samples from this study, alternative feed additive combinations, and dose rates of feed additives should be matters for further investigation.

\section{ACKNOWLEDGMENTS}

This study was supported by SBScibus (Camden, NSW, Australia), The University of Sydney (Camden, NSW, Australia), Dairy Australia (Southbank, VIC, Australia), Elanco Animal Health (West Ryde, Australia), and Lallemand Animal Nutrition (Maroochydore, Queensland, Australia). The authors thank Phibro Animal Health Pty. Ltd. (Girraween, NSW, Australia) and Weston Milling (Enfield, NSW, Australia) for donating products. The authors also thank The University of Sydney Poultry Unit for use of the cold pellet press, and staff at SBScibus, The Dairy Science Group (The University of Sydney, Camden, NSW, Australia), Craigend (The Oaks, NSW, Australia), A. D. Pastoral (Mt. Hunter, NSW, Australia), and Vielun Park (Cobbitty, NSW, Australia) for their technical assistance and P. Thomson (The University of Sydney, Camden, NSW, Australia) for statistical advice. The authors acknowledge D. Balzer, H. Thurlow (SBScibus, Camden, NSW, Australia), H. Irvine, J. Schuler, S. Razak (The University of Sydney, Camden, NSW, Australia), C. Johnston, A. Lean, A. Robins, and B. Tett (Charles Sturt University, Wagga Wagga, NSW, Australia) for their laboratory and farm assistance.

\section{REFERENCES}

Arambel, M. J., R. D. Wiedmeier, D. H. Clark, R. C. Lamb, R. L. Boman, and J. L. Walters. 1988. Effect of sodium bicarbonate and magnesium oxide in an alfalfa-based total mixed ration fed to early lactating dairy cattle. J. Dairy Sci. 71:159-163.

Asanuma, N., and T. Hino. 2002. Understanding metabolic regulation in the ruminal bacteria: Streptococcus bovis, Selenomonas ruminantium, and Megasphaera elsdenii. Pages 61-87 in Gastrointestinal Microbiology in Animals. S. A. Martin, ed. Research Signpost, Kerala, India.

Bevans, D. W., K. A. Beauchemin, K. S. Schwartzkopf-Genswein, J. J. McKinnon, and T. A. McAllister. 2005. Effect of rapid or gradual grain adaptation on subacute acidosis and feed intake by feedlot cattle. J. Anim. Sci. 83:1116-1132.

Bramley, E., I. J. Lean, W. J. Fulkerson, and N. D. Costa. 2012. Feeding management and feeds on dairy farms in New South Wales and Victoria. Anim. Prod. Sci. 52:20-29.

Bramley, E., I. J. Lean, W. J. Fulkerson, M. A. Stevenson, A. R. Rabiee, and N. D. Costa. 2008. The definition of acidosis in dairy herds predominantly fed on pasture and concentrates. J. Dairy Sci. 91:308-321.

Britton, R., R. Stock, and U. Cornell. 1989. Acidosis-A continual problem in cattle fed high grain diets. Pages 8-15 in Proc. 1989 Cornell Nutrition Conference for Feed Manufacturers. Cornell University, Ithaca, NY

Brown, M. S., C. R. Krehbiel, M. L. Galyean, M. D. Remmenga, J. P. Peters, B. Hibbard, J. Robinson, and W. M. Moseley. 2000. Evaluation of models of acute and subacute acidosis on dry matter intake, ruminal fermentation, blood chemistry, and endocrine profiles of beef steers. J. Anim. Sci. 78:3155-3168.

Burrin, D. G., and R. A. Britton. 1986. Response to monensin in cattle during subacute acidosis. J. Anim. Sci. 63:888-893.

Celi, P. 2011. Biomarkers of oxidative stress in ruminant medicine Immunopharmacol. Immunotoxicol. 33:233-240.

Clary, E. M., R. T. Brandt, D. L. Harmon, and T. G. Nagaraja. 1993 Supplemental fat and ionophores in finishing diets: Feedlot performance and ruminal digesta kinetics in steers. J. Anim. Sci. 71:3115-3123

Clayton, E. H., I. J. Lean, J. B. Rowe, and J. W. Cox. 1999. Effects of feeding virginiamycin and sodium bicarbonate to grazing lactating dairy cows. J. Dairy Sci. 82:1545-1554.

Cocito, C. 1979. Antibiotics of the virginiamycin family, inhibitors which contain synergistic components. Microbiol. Rev. 43:145192.

Coe, M. L., T. G. Nagaraja, Y. D. Sun, N. Wallace, E. G. Towne, K. E. Kemp, and J. P. Hutcheson. 1999. Effect of virginiamycin on ruminal fermentation in cattle during adaptation to a high concentrate diet and during an induced acidosis. J. Anim. Sci. 77:2259-2268.

da Silva-Kazama, D. C., C. Côrtes, R. Kazama, C. Benchaar, G. T. D Santos, L. M. Zeoula, and H. V. Petit. 2011. Ruminal fermentation characteristics and fatty acid profile of ruminal fluid and milk of dairy cows fed flaxseed hulls supplemented with monensin. J. Dairy Res. 78:56-62.

Danscher, A. M., H. L. Enemark, P. H. Andersen, B. Aalbæk, and O. L. Nielsen. 2010. Polysynovitis after oligofructose overload in dairy cattle. J. Comp. Pathol. 142:129-138.

de Ondarza, M. B., C. J. Sniffen, L. Dussert, E. Chevaux, J. Sullivan, and N. Walker. 2010. Case study: Multiple-study analysis of the effect of live yeast on milk yield, milk component content and yield, and feed efficiency. Prof. Anim. Sci. 26:661-666.

Dennis, S. M., T. G. Nagaraja, and E. E. Bartley. 1981. Effect of lasalocid or monensin on lactate-producing or using rumen bacteria. J. Anim. Sci. 52:418-426.

Dirksen, G. U., H. G. Liebich, and E. Mayer. 1985. Adaptive changes of the ruminal mucosa and their functional and clinical significance. Bovine Pract. 20:116-120.

Duffield, T., J. C. Plaizier, A. Fairfield, R. Bagg, G. Vessie, P. Dick, J. Wilson, J. Aramini, and B. McBride. 2004. Comparison of techniques for measurement of rumen $\mathrm{pH}$ in lactating dairy cows. J. Dairy Sci. 87:59-66. 
Dunlop, R. H., and P. B. Hammond. 1965. D-Lactic acidosis of ruminants. Ann. N. Y. Acad. Sci. 119:1109-1132.

Erdman, R. A. 1988. Dietary buffering requirements of the lactating dairy cow: A review. J. Dairy Sci. 71:3246-3266.

Gabai, G., S. Testoni, R. Piccinini, L. Marinelli, and G. Stradaioli. 2004. Oxidative stress in primiparous cows in relation to dietary starch and the progress of lactation. Anim. Sci. 79:99-108.

Ghorbani, B., T. Ghoorchi, H. Amanlou, and S. Zerehdaran. 2011. Effects of using monensin and different levels of crude protein on milk production, blood metabolites and digestion of dairy cows. Asian-australas. J. Anim. Sci. 24:65-72.

Golder, H. M., P. Celi, and I. J. Lean. 2013a. Ruminal acidosis in 21-month-old Holstein heifer. Can. Vet. J. In press.

Golder, H. M., P. Celi, A. R. Rabiee, C. Heuer, E. Bramley, S. W. Miller, R. King, and I. J. Lean. 2012. Effects of grain, fructose and histidine on ruminal $\mathrm{pH}$ and fermentation products during an induced subacute acidosis protocol. J. Dairy Sci. 95:1971-1982.

Golder, H. M., I. J. Lean, A. R. Rabiee, R. King, and P. Celi. 2013b. Effects of grain, fructose, and histidine feeding on endotoxin and oxidative stress measures in dairy heifers. J. Dairy Sci. 96:78817891. http://dx.doi.org/10.3168/jds.2013-7113.

González, L. A., A. Ferret, X. Manteca, and S. Calsamiglia. 2008. Increasing sodium bicarbonate level in high-concentrate diets for heifers. I. Effects on intake, water consumption and ruminal fermentation. Animal 2:705-712.

Gozho, G. N., D. O. Krause, and J. C. Plaizier. 2006. Rumen lipopolysaccharide and inflammation during grain adaptation and subacute ruminal acidosis in steers. J. Dairy Sci. 89:4404-4413.

Harmon, D. L., R. A. Britton, R. L. Prior, and R. A. Stock. 1985. Net portal absorption of lactate and volatile fatty acids in steers experiencing glucose-induced acidosis or fed a $70 \%$ concentrate diet ad libitum. J. Anim. Sci. 60:560-569.

Hedde, R. D., D. G. Armstrong, R. C. Parish, and R. Quach. 1980. Remove from marked records virginiamycin effect on rumen fermentation in cattle. J. Anim. Sci. 51(Suppl. 1):366-367.

Heldt, J. S., R. C. Cochran, G. L. Stokka, C. G. Farmer, C. P. Mathis, E. C. Titgemeyer, and T. G. Nagaraja. 1999. Effects of different supplemental sugars and starch fed in combination with degradable intake protein on low-quality forage use by beef steers. J. Anim. Sci. 77:2793-2802.

Hu, W., and M. R. Murphy. 2005. Statistical evaluation of early- and mid-lactation dairy cow responses to dietary sodium bicarbonate addition. Anim. Feed Sci. Technol. 119:43-54.

Ives, S. E., E. C. Titgemeyer, T. G. Nagaraja, A. del Barrio, D. J. Bindel, and L. C. Hollis. 2002. Effects of virginiamycin and monensin plus tylosin on ruminal protein metabolism in steers fed corn-based finishing diets with or without wet corn gluten feed. J. Anim. Sci. 80:3005-3015.

Kennelly, J. J., B. Robinson, and G. R. Khorasani. 1999. Influence of carbohydrate source and buffer on rumen fermentation characteristics, milk yield, and milk composition in early-lactation Holstein cows. J. Dairy Sci. 82:2486-2496.

Kilmer, L. H., L. D. Muller, and T. J. Snyder. 1981. Addition of sodium bicarbonate to rations of postpartum dairy cows: Physiological and metabolic effects. J. Dairy Sci. 64:2357-2369.

Kleen, J. L., G. A. Hooijer, J. Rehage, and J. P. T. M. Noordhuizen. 2003. Subacute ruminal acidosis (SARA): A review. J. Vet. Med. A Physiol. Pathol. Clin. Med. 50:406-414.

Kowalik, B., J. Skomiał, J. J. Pająk, M. Taciak, M. Majewska, and G. Bełżecki. 2012. Population of ciliates, rumen fermentation indicators and biochemical parameters of blood serum in heifers fed diets supplemented with yeast (Saccharomyces cerevisiae) preparation. Anim. Sci. Pap. Rep. 30:329-338.

Lean, I. J., H. M. Golder, J. L. Black, R. King, and A. R. Rabiee. 2013. In vivo indices for predicting acidosis risk of grains in cattle: Comparison with in vitro methods. J. Anim. Sci. 91:2823-2835.

Lean, I. J., L. K. Wade, M. A. Curtis, and J. Porter. 2000. New approaches to control of ruminal acidosis in dairy cattle. Asianaustralas. J. Anim. Sci. 13(Suppl.):266-269.

Lodge-Ivey, S. L., J. Browne-Silva, and M. B. Horvath. 2009. Technical note: Bacterial diversity and fermentation end products in rumen fluid samples collected via oral lavage or rumen cannula. J. Anim. Sci. 87:2333-2337.

Marounek, M., K. Fliegrova, and S. Bartos. 1989. Metabolism and some characteristics of ruminal strains of Megasphaera elsdenii. Appl. Environ. Microbiol. 55:1570-1573.

Morris, F. E., M. E. Branine, M. L. Galyean, M. E. Hubbert, A. S. Freeman, and G. P. Lofgreen. 1990. Effect of rotating monensin plus tylosin and lasalocid on performance, ruminal fermentation, and site and extent of digestion in feedlot cattle. J. Anim. Sci. 68:3069-3078.

Mutsvangwa, T., J. P. Walton, J. C. Plaizier, T. F. Duffield, R. Bagg, P. Dick, G. Vessie, and B. W. McBride. 2002. Effects of a monensin controlled-release capsule or premix on attenuation of subacute ruminal acidosis in dairy cows. J. Dairy Sci. 85:3454-3461.

Nagaraja, T. G., M. B. Taylor, D. L. Harmon, and J. E. Boyer. 1987. In vitro lactic acid inhibition and alterations in volatile fatty acid production by antimicrobial feed additives. J. Anim. Sci. 65:1064-1076

Nagaraja, T. G., and E. C. Titgemeyer. 2007. Ruminal acidosis in beef cattle: The current microbiological and nutritional outlook. J. Dairy Sci. 90(E-Suppl.):E17-E38.

Nordlund, K. V., and E. F. Garrett. 1994. Rumenocentesis: A technique for collecting rumen fluid for the diagnosis of subacute rumen acidosis in dairy herds. Bovine Pract. 28:109-112.

O'Grady, L., M. L. Doherty, and F. J. Mulligan. 2008. Subacute ruminal acidosis (SARA) in grazing Irish dairy cows. Vet. J. 176:4449.

Owens, F. N., D. S. Secrist, W. J. Hill, and D. R. Gill. 1998. Acidosis in cattle: A review. J. Anim. Sci. 76:275-286.

Pesce, A. J., and L. A. Kaplan. 1996. Clinical Chemistry Infobase: A Scientific \& Management Cyclopedia. Pages 2246-2320. PesceKaplan Publishers, Cincinnati, OH.

Plaizier, J. C., D. O. Krause, G. N. Gozho, and B. W. McBride. 2008. Subacute ruminal acidosis in dairy cows: The physiological causes, incidence and consequences. Vet. J. 176:21-31.

Plaizier, J. C., A. Martin, T. Duffield, R. Bagg, P. Dick, and B. W. McBride. 2000. Effect of a prepartum administration of monensin in a controlled-release capsule on apparent digestibilities and nitrogen utilization in transition dairy cows. J. Dairy Sci. 83:2918-2925.

Poos, M. I., T. L. Hanson, and T. J. Klopfenstein. 1979. Monensin effects on diet digestibility, ruminal protein bypass and microbial protein synthesis. J. Anim. Sci. 48:1516-1524.

RAGFAR (Reference Advisory Group on Fermentative Acidosis of Ruminants). 2007. Ruminal acidosis-Aetiopathogenesis, prevention and treatment: A review for veterinarians and nutritional professionals. A. V. Association, ed. Blackwell Publishing Asia Pty. Ltd., Carlton, Victoria, Australia.

Ramanzin, M., L. Bailoni, S. Schiavon, and G. Bittante. 1997. Effect of monensin on milk production and efficiency of dairy cows fed two diets differing in forage to concentrate ratios. J. Dairy Sci. 80:1136-1142.

Reinhardt, C. D., M. L. Hands, T. T. Marston, J. W. Waggoner, and L. R. Corah. 2012. Relationships between feedlot health, average daily gain, and carcass traits of Angus steers. Prof. Anim. Sci. 28:11-19.

Salinas-Chavira, J., J. Lenin, E. Ponce, U. Sanchez, N. Torrentera, and R. A. Zinn. 2009. Comparative effects of virginiamycin supplementation on characteristics of growth-performance, dietary energetics, and digestion of calf-fed Holstein steers. J. Anim. Sci. 87:4101-4108.

Shen, J. S., Z. Chai, L. J. Song, J. X. Liu, and Y. M. Wu. 2012. Insertion depth of oral stomach tubes may affect the fermentation parameters of ruminal fluid collected in dairy cows. J. Dairy Sci. 95:5978-5984.

Solorzano, L. C., L. E. Armentano, R. R. Grummer, and M. R. Dentine. 1989. Effects of sodium bicarbonate or sodium sesquicarbonate on lactating Holsteins fed a high grain diet. J. Dairy Sci. $72: 453-461$.

Sprecher, D. J., D. E. Hostetler, and J. B. Kaneene. 1997. A lameness scoring system that uses posture and gait to predict dairy cattle reproductive performance. Theriogenology 47:1179-1187. 
Staples, C. R., and D. S. Lough. 1989. Efficacy of supplemental dietary neutralizing agents for lactating dairy cows. A review. Anim. Feed Sci. Technol. 23:277-303.

Stokes, M. R., L. L. Vandemark, and L. S. Bull. 1986. Effects of sodium bicarbonate, magnesium oxide, and a commercial buffer mixture in early lactation cows fed hay crop silage. J. Dairy Sci. 69:1595-1603

Sunderman, F. W., Jr., and S. Nomoto. 1970. Measurement of human serum ceruloplasmin by its $p$-phenylenediamine oxidase activity. Clin. Chem. 16:903-910.

Supelco Inc. 1975. GC separation of VFA C2-C5. Bulletin 749. Supelco Inc., Bellefonte, PA.

Thrune, M., A. Bach, M. Ruiz-Moreno, M. D. Stern, and J. G. Linn. 2009. Effects of Saccharomyces cerevisiae on ruminal $\mathrm{pH}$ and microbial fermentation in dairy cows: Yeast supplementation on rumen fermentation. Livest. Sci. 124:261-265.
Valentine, S. C., E. H. Clayton, G. J. Judson, and J. B. Rowe. 2000 Effect of virginiamycin and sodium bicarbonate on milk production, milk composition and metabolism of dairy cows fed high levels of concentrates. Aust. J. Exp. Agric. 40:773-781.

Van Nevel, C. J., D. I. Demeyer, and H. K. Henderickx. 1984. Effect of virginiamycin on carbohydrate and protein-metabolism in the rumen in vitro. Arch. Tierernähr. 34:149-155.

Yang, C. M., and J. B. Russell. 1993. The effect of monensin supplementation on ruminal ammonia accumulation in vivo and the numbers of amino acid-fermenting bacteria. J. Anim. Sci. 71:3470-3476.

Želvytė, R., I. Monkevičenè, J. Balsytè, A. Sederevičius, J. Laugalis, and V. Oberauskas. 2006. The effect of probiotic Levucell SC ${ }^{\circledR}$ on the activity of fermentative processes in the rumen of dairy cows and their productivity. Vet. Med. Zoot. 36:91-96. 